\title{
Fotoquímica de Corantes (e outras moléculas orgânicas) em Superfícies
}

LUIS FILIPE VIEIRA FERREIRA*

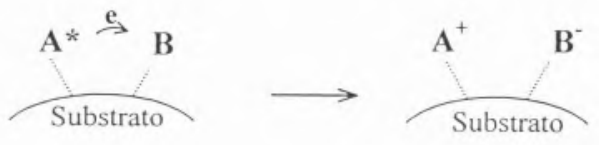

Substrato electronicamente inerte

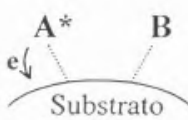

Substrato -
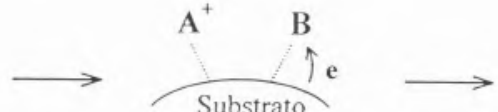

(e)

\section{Substrato electronicamente activo}

\section{BREVE INTRODUÇÃO \\ À FOTOQUÍMICA DE SUPERFÍCIES}

Há um interesse crescente no estudo de fotoprocessos de moléculas no estado adsorvido, quer fisicamente adsorvidas quer quimicamente ligadas a superfícies sólidas, a grânulos, pós ou géis [1-5]. Adsorventes comuns são óxidos como a sílica, a alumina, os alumino-silicatos, as argilas, entre outros. Alguns estudos, embora mais raros, foram também apresentados em celulose e derivados e amido [2a].

Numa grande variedade de suportes sólidos a natureza e o número de grupos reactivos superficiais afectam drasticamente a distribuição e organização local dos adsorvatos. O pré-tratamento e o manuseamento do adsorvente, o solvente usado para a deposição da sonda, todos estes efeitos afectam a superfície e consequentemente o modo de adsorção das sondas. Daqui resulta que a fotoquímica e a fotofísica dos adsorvatos varia como consequência deste pré-tratamento.

Existem normalmente dois objectivos nestes estudos: observar como as interaç̧ões com a superfície modificam o comportamento das sondas nos estados excitado e fundamental e também como usar a fotoquímica como ferramenta para sondar a superfície de um substrato.

Fig. 1 - Tipos de substrato.

Para além do interesse nos substratos já citados que podemos designar por "electronicamente inertes", deve também referir-se que há uma actividade extensa no campo dos "substratos electronicamente activos", nomeadamente os semicondutores.

Nestes sistemas é o substrato que absorve a radiação de excitação, produzindo-se electrões e lacunas, que após a chegada à superfície reagem com os adsorvatos. Podem também promover a extinção dos estados excitados da molécula adsorvida após a transferência electrónica sonda-superfície. Não iremos neste trabalho abordar nenhum destes casos.

\subsection{Alguns trabalhos pioneiros}

Os estudos iniciais de fotoquímica e fotofísica de moléculas adsorvidas são relativamente recentes e foram feitos nos anos 60 (à parte os estudos de Boer e colaboradores nos anos 30 [6]). Leermakers [7] apresentou um excelente artigo de revisão onde inclui os seus trabalhos relativos a cetonas adsorvidas em sílica gel e estudos de isomerização cis-trans do estilbeno em sílica, fotocro- mismo do espiropirano e foto-clivagem de ciclo-hexadienonas.

Estes estudos mostraram claramente que, em muitos casos, existiram mudanças energéticas e da natureza do estado electronicamente excitado após adsorção. Como consequência, as eficiências dos inúmeros processos fotofísicos e fotoquími$\cos$ são alteradas. A interacção do adsorvato com o suporte é simultaneamente não-específica ou específica - nomeadamente interacções com os grupos activos da superfície (hidroxilos na superfície dos óxidos, por exemplo). As forças interactivas responsáveis pela adsorção podem ser electrostáticas, de dispersão ou ligações de hidrogénio.

O estudo do modo de ligação do adsorvato à superfície pode ser feito por utilização de várias técnicas espectroscópicas e não espectroscópicas [4, 2a]. Dentro das primeiras é de referir em especial a reflectância difusa para estudos de absorção e emissão no ultra-violeta, visível e infra-vermelho próximo, a espectroscopia de fotoelectrão de raios-X (XPS) e o infravermelho com transformada de Fourier (FTIR). No segundo grupo é de referir a determinação de calores de adsorção e de isotérmicas de adsorção, entre outras. 
É desnecessário enfatizar a importância de um conhecimento detathado da estrutura da superfície e da sua modificação sob várias condições experimentais.

Vamos referir aqui alguns dos estudos fotoquímicos iniciais em sílica gel, vidro Vycor poroso, alumina e alguns zeólitos. Já nos anos 70 e 80 . salientam-se os trabalhos de vários grupos: nomeadamente P. de Mayo, W.R. Ware e colaboradores, em superfícies de sílica [8], D. Oelkrug e colaboradores [9] e J.K. Thomas e colaboradores [10a] com estudos com várias sondas em superfícies de alumina entre outras, N.J. Turro, J.C. Scaiano com interessantes trabaIhos em sílica, zeólitos e outras superfícies $[11,12]$, isto só para citar alguns dos trabalhos mais relevantes que deram uma base sólida a esta nova disciplina.

F. Wilkinson e colaboradores desenvolveram nos anos 80 a técnica de Fotólise de Impulso de Laser em Modo de Reflectância Difusa [1, 13], essencial para os estudos de absorção e emissão transiente em superfícies, que se revelou tão importante para os estudos de meios opacos como foi, a partir da sua descoberta nos anos 50, a fotólise convencional em transmissão para meios transparentes.

Vamos resumidamente referir alguns destes trabalhos iniciais que consideramos significativos:

Devido ao longo tempo de vida do monómero, à capacidade de formação de excímeros e à sensibilidade espectral, o pireno foi uma das sondas mais usadas nestes estudos iniciais. A razão das bandas vibrónicas III/I (370 nm/390 nm) foi usada com sucesso para monitorar a polaridade microscópica do meio ambiente quer de sílica, quer de alumina [10]. O pico I (a banda 0-0 da absorção $\mathrm{S}_{0} \rightarrow \mathrm{S}_{1}$, proibida por simetria, cresce em meios polares). Verificou-se no caso da alumina, que esta superfície apresenta uma polaridade superficial semelhante à de solventes polares (por exemplo o metanol) [10a].

Na superfície de sílica, o pireno apresenta uma razão molar III/I que também caracteriza a superfície como francamente polar e hidrofílica. No entanto, a derivatização com cloro-trimetilsilano revelou muito maiores razões III/I, evidenciando assim o aumento da hidrofobicidade da superfície devido ao pré-tratamente referido. A co-adsorção de solvente faz também variar as razões III/I, ou seja a hidrofilia ou hidrofobicidade das superfícies de sílica [10b].

P. de Mayo e colaboradores [8] e outros autores [14, 15] usaram alguns hidrocarbonetos policíclicos aromáticos (HPAs) como o naftaleno, o pireno e o antraceno para estudar quer a mobilidade superficial destas moléculas adsorvidas, quer os efeitos de agregação. A percentagem de cobertura da superfície (expressa muitas vezes em \% de monocamada) é determinante quanto a estes dois aspectos acima referidos. As moléculas de HPAs com os seus sistemas de electrões interagem com o substrato formando ligações de hidrogénio, desde que factores estereoquímicos, ou a água fisicamente adsorvida (que impede a interacção directa sonda-substrato) o não impeçam. A interaç̧ão também pode ser feita com pares de electrões não ligantes em moléculas que os possuam.

As emissões de fluorescência destes hidrocarbonetos policíclicos aromáticos adsorvidos (quer dos monómeros, quer dos excímeros) são normalmente multi-exponenciais, de acordo com a heterogeneidade do adsorvente e revelando múltiplas situações de adsorção. Frequentemente esses decaimentos multi-exponenciais são analisados com duas ou três componentes:

$I(t)=a_{1} e^{-t / \tau_{1}}+a_{2} e^{-t / \tau_{2}}+a_{3} e^{-t / \tau_{3}}$

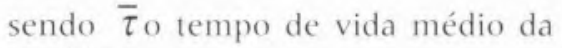
espécie

$$
\bar{\tau}=\sum a_{i} \tau_{i}^{2} / \sum a_{i} \tau_{i}
$$

e $f_{i}=a_{i} \tau_{i} / \sum a_{i} \tau_{i}$ a fracção de moléculas excitadas com tempo de vida $\tau_{i}$. Outros modelos cinéticos foram propostos para a análise de decaimentos em meio heterogéneo $[16,9,10]$.

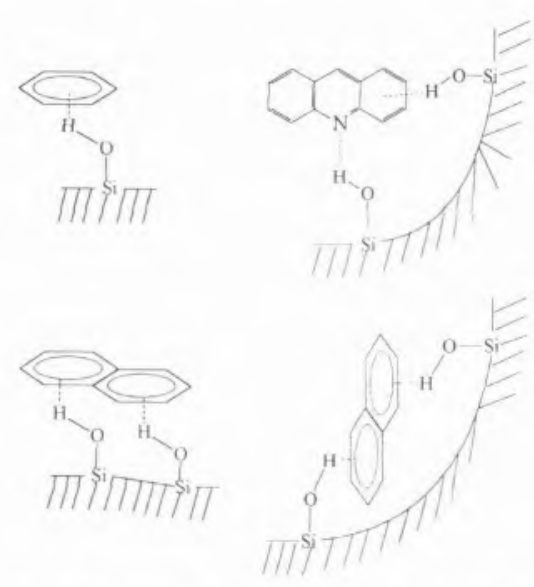

Fig. 2 - Interaçôes dos silanóis da superfície da sílica com hidrocarbonetos aromáticos e com a acridina.

D. Oelkrug e colaboradores [9] usaram, como substratos, aluminas e várias sílicas e, como adsorvatos, vários hidrocarbonetos policíclicos aromáticos, difenilpolienos, acridina e derivados, entre outros. Verificaram que a informação espectroscópica obtida, bem como os decaimentos encontrados, variavam profundamente com o pré-tratamento das superfícies e o modo como a adsorção era feita: assim, no caso da acridina (A) e para superfícies de alumina moderadamente pré-tratadas a baixas temperaturas (i.e. temperaturas de activação $T_{a} \sim 100{ }^{\circ} \mathrm{C}$ ), as ligações são essencialmente de hidrogénio e há protonação do adsorvido $\left(\mathrm{AH}^{+}\right)$. No caso da sílica activada a $300^{\circ} \mathrm{C}$ a absorção no estado fundamental e a emissão de fluorescência são semeIhantes às obtidas em água e etanol, sugerindo que a espécie ligada ao substrato por pontes de hidrogénio é a única espécie emissiva.

$\mathrm{O}$ tratamento da $\mathrm{Al}_{2} \mathrm{O}_{3}$ a altas temperaturas $\left(600{ }^{\circ} \mathrm{C}\right)$ resulta na formação de complexos $A \sigma^{+}$entre os pares de electrões desemparelhados do azoto da acridina e os sítios ácidos de Lewis da alumina, em prejuízo das espécies $\mathrm{AH}^{+}$desfavorecidas pela desidroxilação.

A acidez de superfícies como o vidro poroso Vycor, foi também estudada usando várias sondas: Lin et al [17] usou 9,10-diazofenantreno 
como aceitador de protões dos sítios ácidos de Brönsted da superfície, que se vão ligar aos átomos de azoto da molécula.

Suzuki e Fujii [18] usaram a acridona como sonda para testar o resultado de vários pré-tratamentos de sílica. Os resultados obtidos para a emissão de fluorescência da acridona, adsorvida em sílica (simplesmente desidratada por aquecimento a $200^{\circ} \mathrm{C}$ sob pressão reduzida $\left.\sim 10^{-6} \mathrm{mbar}\right)$, são comparados com as emissões em benzeno, etanol e $\mathrm{H}_{2} \mathrm{SO}_{4} 18 \mathrm{~N}$.

A principal conclusão tirada é a de que a principal espécie emissiva na superfície da sílica pré-tratada a $200^{\circ} \mathrm{C}$ em vácuo é a acridona fortemente ligada por ligações de hidrogénio aos silanóis da superfície da sílica (o carbonilo da acridona ou da N-metilacridona interage com os hidroxilos superficiais e o grupo amino pouco interage com a superfície). A espécie protonada também emite na superfície da sílica embora esta componente da emissão tenha menor peso.

São de citar ainda trabalhos em que foram usados corantes como a Rodamina B, a Rodamina $6 \mathrm{G}$ e outros xantenos como sondas para o estudo de superfícies de cristais orgânicos, fluoreto de cálcio e placas de quartzo [19].

Em todos os exemplos citados até aqui foram usadas, como sondas, moléculas em estados excitados singuleto, com tempos de vida relativamente curtos, normalmente na gama temporal do nanosegundo.

O uso de sondas tripleto é extremamente interessante uma vez que as moléculas adsorvidas apresentam usualmente tempos de vida mais longos, aproximando-se em muitas circunstâncias dos valores obtidos em matrizes rígidas. Estes estados excitados mais longos podem aumentar as eficiências dos processos fotoquímicos em causa, pelo que os estudos espectroscópicos e cinéticos assim realizáveis são de uma diversidade e interesse notáveis.

Iremos também apresentar exemplos de alguns estudos com moléculas de elevado rendimento quântico de cruzamento intersiste- mas, mas antes é necessário referir os métodos de preparação de amostras, falar das características de alguns substratos e também de métodos experimentais específicos usados nestes estudos.

\section{2 "Pastas" (slurries), amostras por "evaporação forçada" e por "equilíbrio"}

A adsorção de sondas na superfície da celulose microcristalina ou nativa, na superfície de sílicas de diferentes porosidades (ou alumina) e ainda de silicalite (e outros zeólitos) é feita de um modo diferenciado e de acordo com as características de cada adsorvente como referiremos no parágrafo 2 .
A adsorção nestes adsorventes em pó pode ser feita a partir de soluções ou de uma fase gasosa.

Em termos gerais, interessa dizer que um dos métodos mais usados é o da evaporação do solvente (após adição de uma solução ao substrato sólido em pó previamente seco e/ou activado). A mistura (slurry) pode ser seca em "hotte" ou num evaporador rotativo, sendo a remoção final do solvente feita sob vácuo a $\sim 10^{-3} \mathrm{mbar}$. A vantagem deste método é um conhecimento rigoroso da concentração do adsorvido, o que possibilita o traçado de espectros de absorção (reflectância difusa no estado fundamental) a partir dos quais se pode calcular o coeficiente de extinção molar da

\section{Preparação de Amostras}

\section{Amostras em Pasta ("Slurry")}

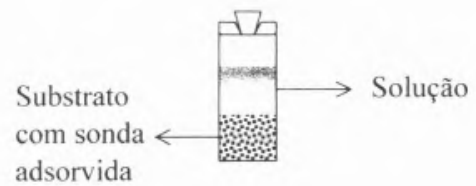

\section{Amostras por "Deposicão"}

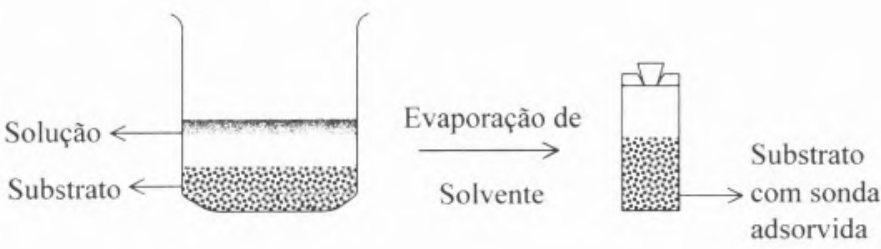

\section{Amostras por "Equilibrio"}
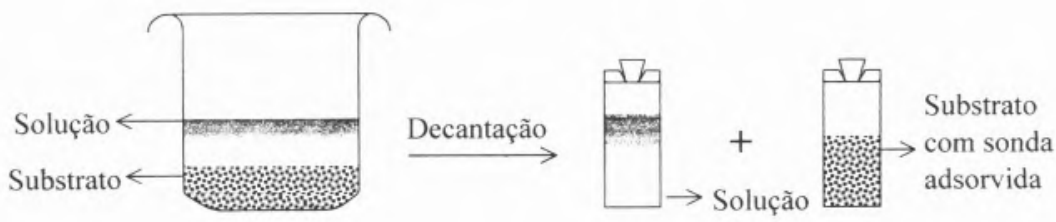

Fig. 3 - Preparação de amostras. 
sonda adsorvida no sólido, que pode ser comparado ao obtido por absorção em amostras transparentes (soluções homogéneas ou filmes), com o uso da lei de Beer.

Uma alternativa é a remoção por filtração da solução em contacto prolongado com a amostra, seguida de evaporação rigorosa do resto do solvente. O cálculo da concentração do adsorvido pode ser feito determinando-se a concentração de sonda no líquido em equilíbrio com o sólido. Este método tem a desvantagem de com facilidade se cometerem erros significativos por evaporação do solvente, ou outros. A vantagem é a de se obter amostras de "equilíbrio" em que a sonda se reparte pelo adsorvente e pela solução de acordo com a termodinâmica em questão em cada caso. O equilíbrio existente entre as moléculas de soluto e de adsorbato é dinâmico: as moléculas adsorvidas passam para a solução e as da solução passam ao estado adsorvido. Não há portanto agregação "forçada" pela evaporação do solvente.

Após a remoção do solvente encontram-se, nos espectros de absorção da sonda, desvios espectrais quer para o vermelho, quer para o azul, em qualquer dos casos para coberturas de sonda inferiores à monocamada. Podem também detectar-se alargamentos das bandas de absorção, novas bandas de absorção ou mudança nos coeficientes de extinção das bandas de absorção. A formação de novas espécies pode ter a ver com um efeito de "piscina" durante a evaporação. Uma vez que há um limitado número de "sítios" de adsorção à superfície do adsorvente acessíveis, logo que esses pontos são ocupados por uma primeira molécula, as restantes moléculas interagem com a superfície mais fracamente. À medida que o solvente é removido, a concentração destas moléculas fracamente ligadas vai aumentar na fase líquida, aumentando a tendência para formar quer agregados superiores no estado fundamental quer, mesmo, microcristais à medida que vão sendo adsorvidas à superfície a partir da fase líquida.
A informação das "pastas fluidas" é a mais confusa e mista, reflectindo em simultâneo moléculas de sonda adsorvidas e outras ainda em solução.

Daremos no parágrafo 3 . exemplos de desvios hipsocrómicos e batocrómicos de sondas em superfícies. Apresentaremos exemplos de formação de alguns agregados no estado fundamental em diferentes superfícies.

A grande vantagem da utilização de sondas tripleto de moléculas adsorvidas em superfícies sólidas relativamente aos singuletos é o seu grande tempo de vida, que se aproxima frequentemente do medido em solventes rígidos a baixa temperatura.

O desenvolvimento de técnicas apropriadas a estes estudos foi feito no início dos anos 80 e durante os anos 90, nomeadamente a Fotólise de Impulso de Laser em Modo de Reflectância Difusa, revelou-se essencial para a realização quer de estudos espectroscópicos quer cinéticos em superfícies. Para este desenvolvimento experimental foi decisiva a contribuição do Prof. Frank Wilkinson da Loughborough University no Reino Unido $[1,13,20]$

Retomaremos este tema no parágrafo 4. Antes disso vamos abordar a caracterização de algumas das superfícies por nós usadas na última quinzena de anos de trabalho.

\section{ALGUNS SUBSTRATOS SÓLIDOS EM PÓ: A CELULOSE, A SÍLICA E A SILICALITE.}

Celulose.

A celulose tem sido usada como substrato para o estudo de processos fotoquímicos e fotofísicos de várias sondas, com relevo para os corantes. Algumas das propriedades deste substrato, nomeadamente a capacidade de adsorver moléculas quer no seu seio, quer à superfície das cadeias do polímero natural (com formação em muitos casos de ligações de hidrogénio) e ainda a não difusibilidade do oxigénio no seu seio [2]26], tornam-no particularmente atraente para a realização de estudos de luminescência à temperatura ambiente. Publicámos recentemente alguns estudos da fluorescência ou fosforescência de corantes rodamínicos [27-29], auramina O [27b], cetonas [30], 2,3-naftalimidas [31], oxazina [32], laranja de acridina [33], e cianinas [34-36] adsorvidos em celulose.

Nestes estudos foi usada a celulose microcristalina, cuja fórmula estrutural se apresenta na Figura 4.

Estruturalmente a celulose é um polímero da D-glucose no qual as unidades individuais estão unidas por ligações $\beta$-glicosídicas entre o carbono anomérico de uma das unidades e o grupo hidroxilo em $\mathrm{C}_{4}$ da unidade seguinte $[21,22]$. A celulose é provavelmente o composto orgânico mais abundante na terra. É o principal componente estrutural das células vegetais. A resistência da madeira provém principalmente das ligações de hidrogénio entre os grupos hidroxilo de uma cadeia e os das cadeias vizinhas. Estas ligações de hidrogénio são muito favorecidas pela estrutura linear do polímero natural com conformações que permitem a ocorrência dessas interacções, ao contrário do que se verifica no amido onde, também por motivos

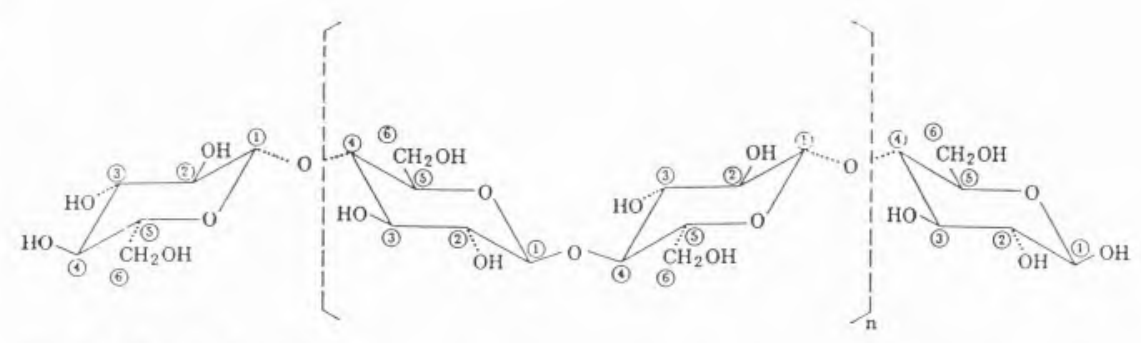

Fig. 4 - Estrutura da celulose. 
estruturais, as cadeias, embora possam ser lineares, não podem adquirir uma conformação rectilínea.

Estudos de raios - X mostraram que a celulose nativa é um sistema de duas fases: uma amorfa, menos ordenada e compacta, localizada à superfície das fibrilas elementares; outra ordenada e compacta (cristalitos) onde as cadeias existem numa forma cristalina definida e fortemente ligadas por ligações de hidrogénio às cadeias mais próximas.

A celulose microcristalina não é mais do que uma forma pura da celulose obtida por um tratamento ácido de celuloses nativas. As regiões amorfas são preferencialmente atacadas e transformadas, sendo o resíduo final altamente cristalino [22]

É bem conhecida a propriedade que as fibras de celulose possuem de incharem (e esticarem) na presença de humidade. Outros solventes polares próticos ou apróticos como o metanol, o etanol, o acetonitrilo e a acetona também promovem o inchamento da celulose microcristalina. No entanto solventes como o benzeno, o tolueno ou o diclorometano não conseguem afastar as cadeias do polímero natural. É assim possível controlar a adsorção de moléculas na celulose microcristalina, à superfície no segundo caso e no seio das cadeias no caso dos solventes que incham o polímero. Após remoção do solvente usado na preparação das amostras, é promovida uma interacção cadeia-hóspede-cadeia que substitui a interacção cadeia-solvente-cadeia anteriormente existente.

Tem particular interesse o estudo da fotodegradação de corantes em celulose seca e húmida, uma vez que este efeito adverso tem importância para a indústria têxtil [37]. Sabemos hoje que um aumento de humidade acarreta uma diminuição de resistência à fotodegradação de muitos corantes, e isto quer para o algodão, quer para outros polímeros onde o corante pode estar adsorvido ou covalentemente ligado [37-39], como a lã embora em menor grau, uma vez que neste caso o mecanismo de degradação é normalmente redutivo,

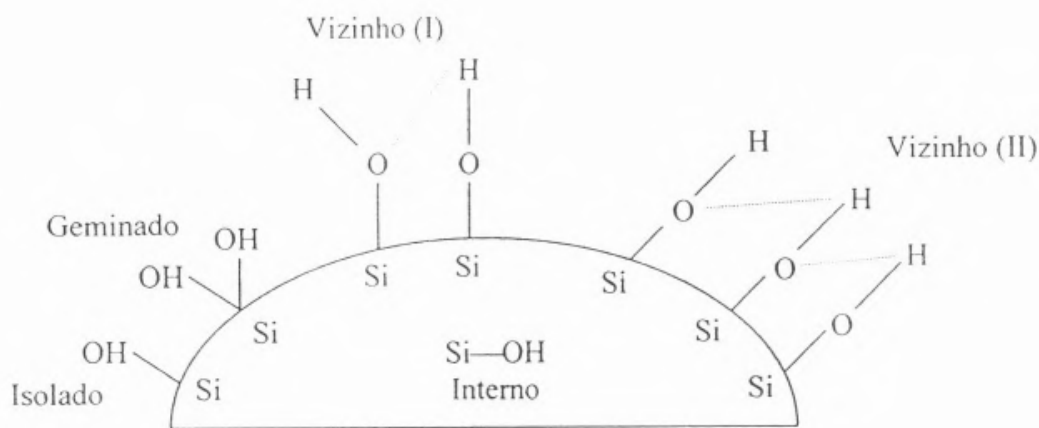

Fig. 5 - Silanóis na estrutura da sílica.

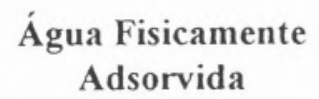

\section{Monocamada \\ de Água}

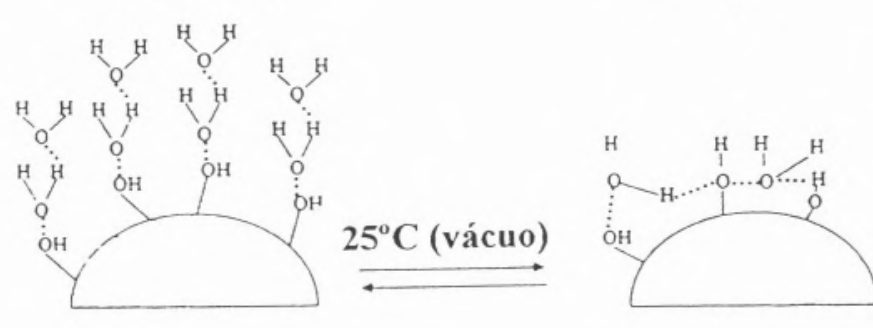

\section{"Superficie Seca" \\ (Sem Água Adsorvida) \\ $\left(8 \mu \mathrm{mol} \mathrm{OH} / \mathrm{m}^{2}\right)$}

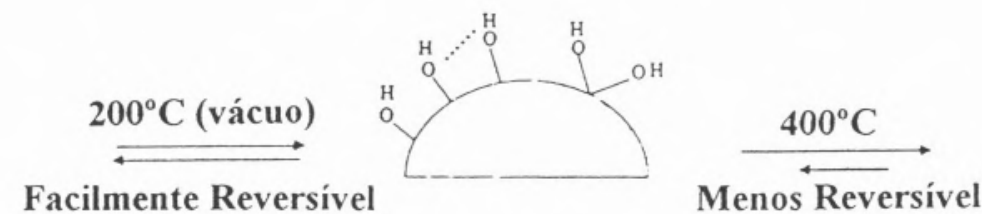

\section{(Sem Silanóis Ligados)

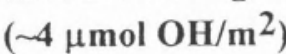

Siloxanos

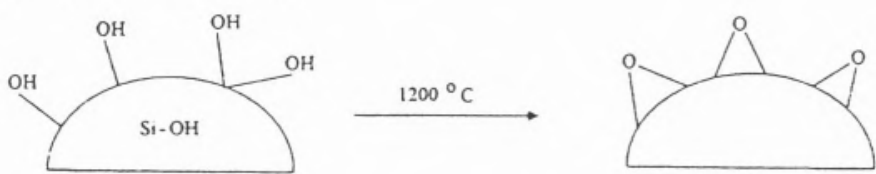

Fig. 6 - Pré-tratamentos para activação da sílica. 
enquanto que na celulose é usualmente oxidativo.

\section{Sílica.}

As sílicas porosas são formas granulares de sílica amorfa, contendo uma rede complexa de poros microscópicos que atraem e retêm água ou solventes orgânicos por meio de adsorção física [40-46]. A sílica porosa tem uma estrutura esponjosa, da qual resulta uma elevada área superficial que varia enormemente com o tamanho do poro (20 a $750 \mathrm{~m}^{2} \mathrm{~g}^{-1}$ ). Esta área superficial corresponde essencialmente à área interna das paredes dos poros. O tamanho médio do poro é normalmente obtido por medidas de área superficial. Dado que mesmo os poros mais pequenos são maiores que a maioria das moléculas, embora da mesma ordem de grandeza, não é de estranhar a ocorrência de restrições quanto à mobilidade. A superfície da sílica porosa contém grupos silanóis ( $\mathrm{Si}-\mathrm{OH})$ e si-
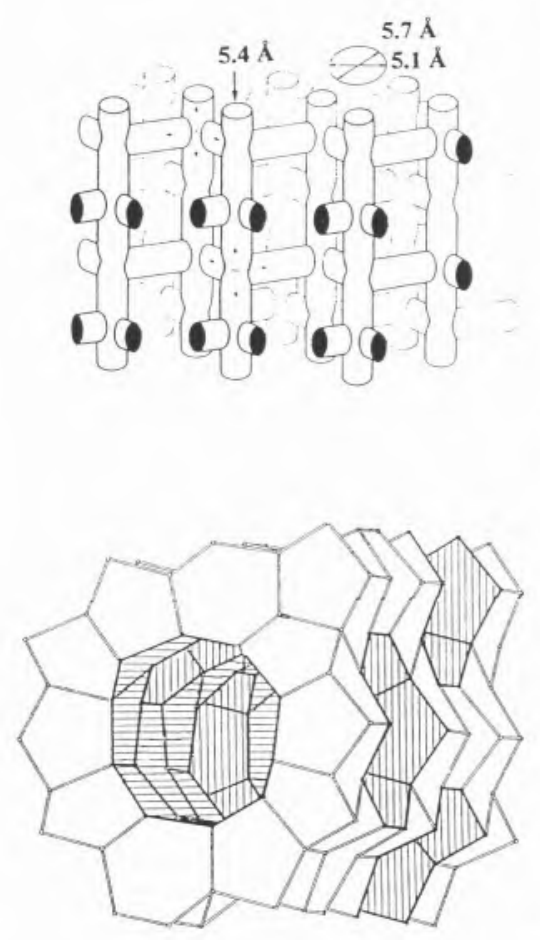

Fig. 7 - Estrutura dos canais da silicalite. loxanos ( $\mathrm{Si}-\mathrm{O}-\mathrm{Si})$. Os silanóis são considerados fortes locais de adsorção, enquanto que os siloxanos são considerados hidrofóbicos [40, 44]. Os silanóis podem ocorrer isolados. vizinhos ou geminados e estar ligados por ligações de hidrogénio à água superficial.

A Figura 5 apresenta esquematicamente os diferentes tipos de silanóis existentes na sílica.

Os trabalhos iniciais de Snyder e Ward (1966) [40] atribuíam maior capacidade de adsorção a silanóis vizinhos aos pares, sendo estes os centros activos responsáveis pela adsorção de sondas à superfície da sílica. Actualmente sabe-se através de estudos de dessorção térmica programada que são os silanóis isolados os mais activos na superfície da sílica. Os silanóis ligados por pontes de hidrogénio têm uma energia de dessorção de $50-60 \mathrm{kcal} \mathrm{mol}^{-1} \mathrm{e}$ os isolados de $\sim 90 \mathrm{kcal} \mathrm{mol}^{-1}[46]$.

Um aquecimento moderado em vácuo $\left(100-120^{\circ} \mathrm{C}\right)$ conduz à remoção da quase totalidade da água fisicamente adsorvida. A última monocamada de água adsorvida só é no entanto removida para uma temperatura de activação da ordem dos $200{ }^{\circ} \mathrm{C}$. O uso de temperaturas mais elevadas $\left(200-1000^{\circ} \mathrm{C}\right)$ conduz à remoção da água quimicamente ligada [44] (ver Figura 6).

Da importância dos grupos hidroxilo, do ponto de vista do processo de adsorção superficial, decorre que quanto maior a percentagem de silanóis activos por unidade de área superficial, maior a eficácia do processo de adsorção. As sílicas de pequenos poros apresentam maior percentagem de silanóis activos do que as de maior poro $[40,41,44]$. Detectou-se nestas superfícies a formação de confórmeros de alguns corantes, dependente quer do tamanho do poro quer do corante em si [29].

\section{Silicalite}

As silicalites são formas muito específicas de zeólitos pentasílicos de pequeno tamanho de poro e, ao contrário dos zeólitos de alumino-silicatos apresenta um carácter hidrofóbi- co e organofílico acentuado. Internamente apresentam canais lineares de secção elíptica $(5.7 \times 5.1 \AA)$, que se cruzam com canais em zig-zag de secção quase circular $(5.40 \pm 2 \AA)$ no caso da silicalite I ou lineares no caso da silicalite II [47, 48]. São caracterizadas pela quase total ausência de alumínio na estrutura, enquanto que os zeólitos ZSM-5 e ZSM-11, embora estruturalmente análogos, apresentam razões $\mathrm{Si} / \mathrm{Al}$ inferiores $[42,48]$. A hidrofobicidade daqueles materiais decorre da ausência de unidades $\mathrm{AlO}_{2}^{-}$na estrutura cristalina

As silicalites são usadas para remoção de compostos orgânicos do seio da água ou de fumos de origem industrial. A inclusão de moléculas orgânicas nos canais impõe restrições conformacionais significativas. A dimensão reduzida do próprio canal permite usar este material com fins selectivos em cromatografia [47b].

\section{ALGUMAS TÉCNICAS EXPERIMENTAIS PARA OS ESTUDOS DE FOTOQUÍMICA DE SUPERFÍCIES}

\subsection{Espectros de reflectância difusa no estado fundamental (UV-Vis-IVP).}

Os espectros de absorção do estado fundamental de amostras sólidas opacas podem obter-se de um modo semelhante ao usado para obtenção de espectros de absorção de amostras transparentes. No segundo caso usa-se a lei de Beer e determinam-se as absorvâncias em função do comprimento de onda. No caso de amostras sólidas, e pelo uso de uma esfera integradora, determinam-se reflectâncias ( $R$ ) em função do comprimento de onda, após calibração do sistema. Um difusor ideal tem reflectância unitária (na prática usa-se, por exemplo, sulfato de bário ou óxido de magnésio, muito puros, que apresentam $\mathrm{R} \sim 0.98 \pm 0.02$ na gama de 200 a 900 nm) e carvão, em partículas finas, que apresenta $\mathrm{R} \sim 0$. Alternativamente pode recorrer-se 
ao uso de padrões comerciais calibrados para o branco e para o preto.

A celulose microcristalina apresenta reflectâncias que se aproximam da unidade no visível (Vis) e infravermelho próximos (IVP) mas têm absorções significativas no ultravioleta (UV). A sílica e a silicalite apresentam igualmente reflectâncias próximas da unidade no Vis e IVP e até a sua absorção no UV é mais reduzida que a da celulose. No caso das sílicas com diferentes porosidades, mas com a mesma granulometria, detectaram-se variações significativas de reflectância.

Consideremos que I e J são os fluxos de luz incidente e dispersa, na mesma direcção e em sentido inverso. O fluxo incidente, I, diminui à medida que penetra na amostra sólida quer porque há absorção de radiação quer porque as partículas dispersam a luz; por outro lado, I é aumentado com a dispersão de J. O fluxo de luz dispersa, J, emergente tem uma variação análoga mas no sentido oposto, como se pode ver na Figura $9[49,50]$.
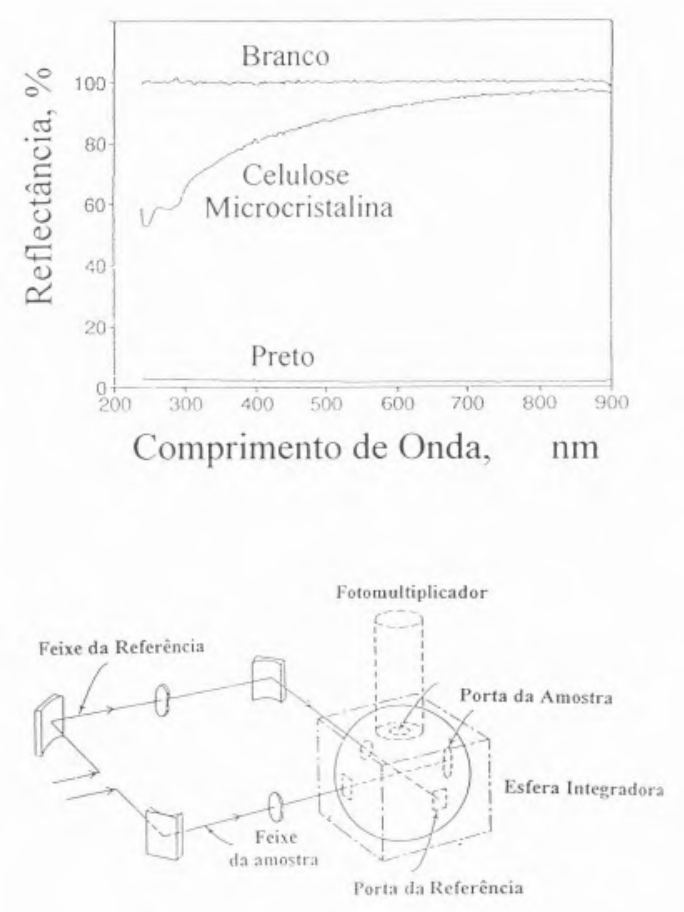

Fig. 8 - Espectros de reflectância difusa no estado fundamental.

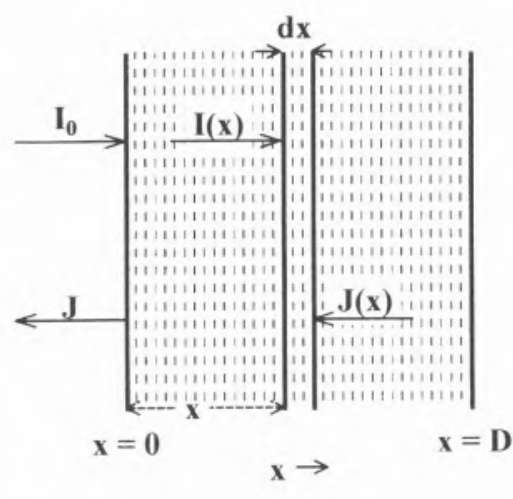

Fig. 9 - Representação esquemática dos feixes de luz incidente (I) e dispersa (J).

pelo que

$d I(x)=-(K+S) I(x) d x+S J(x) d x$ $d J(x)=+(K+S) J(x) d x-S I(x) d x$

onde o coeficiente de absorção é K, e o de dispersão é S. A lei de LambertBeer, para meios transparentes e homogéneos, obtém-se com facilidade considerando que não existe dispersão, ou seja, fazendo $S=0$, pelo que

$$
d I(x)=-K I(x) d x
$$

e portanto $\mathrm{I}=\mathrm{Io} \exp (-\mathrm{Kx})$, onde $\mathrm{K}=\varepsilon \mathrm{C}$, sendo $\varepsilon \mathrm{o}$ coeficiente de absorção neperiano e $\mathrm{C}$ a concentração da espécie absorvedora.

Kubelka e Munk estabeleceram em 1948 que para um difusor ideal e para amostras opticamente densas, ou seja, todas aquelas em que um aumento da espessura não faz variar a reflectância da amostra, a reflectância R é dada por:

$$
\mathrm{R}=\mathrm{J} / \mathrm{I}_{\mathrm{o}}
$$

e $\mathrm{R}$ está relacionada com $\mathrm{K}$ e $\mathrm{S}$ pela função de remissão, $F(R)$

$$
F(R)=(1-R)^{2} /(2 R)=K / S
$$

em que

$$
K(\lambda)=2 \varepsilon(\lambda) C .
$$

sendo agora $\mathrm{K}=2 \varepsilon \mathrm{C}$, onde o factor dois dá conta do aumento médio de distância percorrida pela luz de excitação no difusor ideal.

A função de remissão varia linearmente com o número de cromóforos que absorvem na amostra sólida considerados uniformemente distribuídos. $\mathrm{K}$ e $\mathrm{S}$ são independentes da profundidade de penetração da luz na amostra. Para amostras opticamente espessas, temos que

$$
\begin{aligned}
& \mathrm{I}(\mathrm{x})=\mathrm{I}_{\mathrm{o}} \exp (-\mathrm{b} \mathrm{S} x) \\
& \mathrm{J}(\mathrm{x})=\mathrm{RI}_{\mathrm{o}} \exp (-\mathrm{b} \mathrm{S} \mathrm{x})
\end{aligned}
$$

onde $b=[(1 / 2 R)-R]$, pelo que se define a profundidade de penetração da radiação incidente $\mathrm{x}_{0}$ como:

$$
x_{0}=1 / b S \exp \left(-x / x_{0}\right)
$$

para que $I\left(x_{0}\right)=I_{0} \exp \left(-x / x_{0}\right)$ e $\mathrm{I}\left(\mathrm{x}_{0}\right)=\mathrm{I}_{0}, \mathrm{e}^{-1}$

Se uma amostra tiver mais de um cromóforo a absorver, para amostras opticamente densas podemos escrever

$$
K(\lambda)=K_{B}+2 \sum \varepsilon_{i}(\lambda) C_{i}
$$

onde $K_{B}$ diz respeito ao substrato. Daqui resulta que uma reacção fotoquímica após irradiação do cromóforo adsorvido pode seguir-se temporalmente por um espectro de diferença.

$\Delta \mathrm{K}=\mathrm{S}\left[\mathrm{F}(\mathrm{R})_{\text {irradiado }}-\mathrm{F}(\mathrm{R})_{\text {não irradiado }}\right]$

\subsection{A luminescência induzida por laser com resolução temporal}

Os sistemas de matriz de díodos acoplados a fontes de excitação laser, monocromáticas e de alta fluência, são actualmente uma forma muito atractiva e rigorosa de fazer estudos de luminescência resolvida no tempo. As amostras sólidas opacas obrigam à utilização de geometrias de reflexão, como se mostra na Figura 10. A reflexão especular deve ser evitada de modo a não danificar o detector, que é o coração deste sistema. 


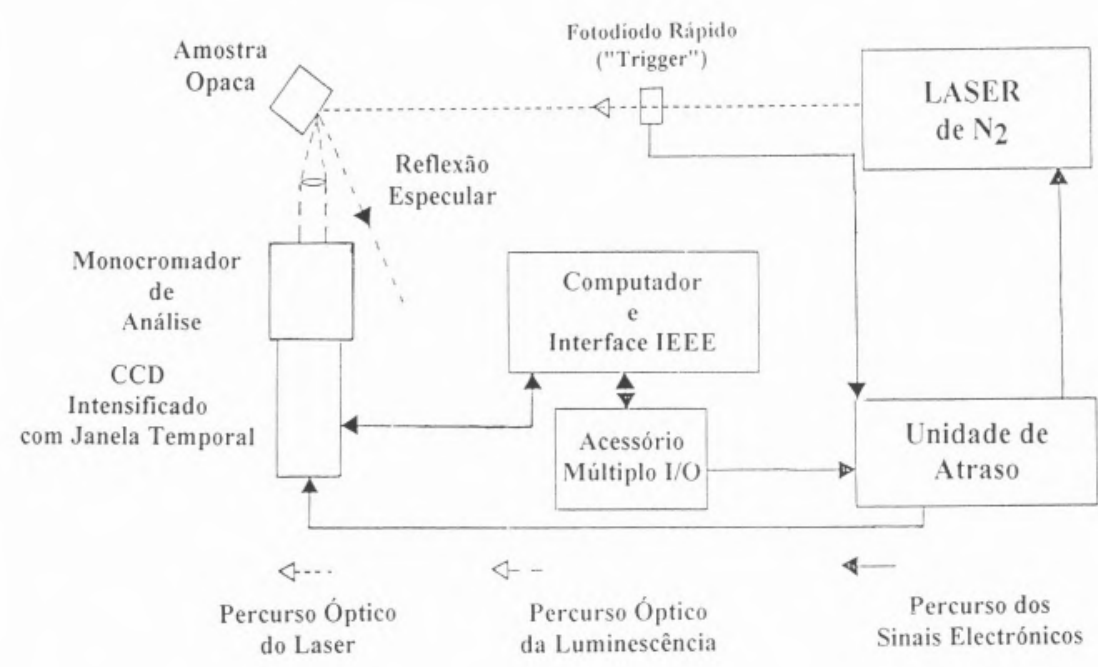

Fig. 10 - Luminescência induzida por laser.

Num passado recente no nosso laboratório passámos a usar um "Charge-Coupled-Device" com intensificador de sinal e janelas tempo-

rais (janela temporal mínima de cerca de 2 ns). Este detector possui uma matriz de díodos $(512 \times 128$ "pixels") na gama espectral do UV-Vis-
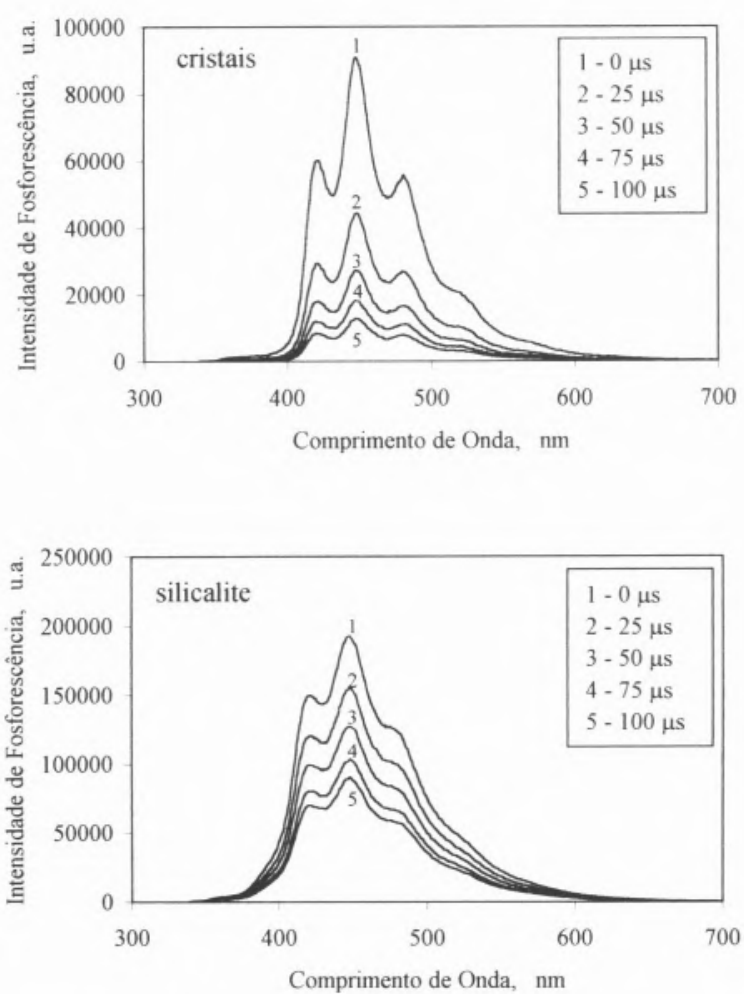

Fig. 11 - Espectros de emissão resolvidos no tempo de a) Cristais de BZP; b) BZP incluída em silicalite.
IVP que permite traçar, com um só impulso do laser, espectros de fluorescência ou de fosforescência na gama espectral citada.

O fotodíodo rápido mede o tempo de disparo do laser $(\mathrm{t}=0)$, a partir do qual se fazem leituras intensificadas ou não, consoante o sinal a detectar. A unidade de atrasos permite, com precisão de picosegundo, atrasar, de um modo pré-programado, as sucessivas leituras da luminescência das amostras e traçar espectros resolvidos no tempo e decaimentos temporais. É assim possível separar a luminescência pronta da atrasada e, portanto, obter espectros de fosforescência e de fluorescência com um só sistema sem recorrer aos métodos clássicos [2].

Apresenta-se na Figura 11 a emissão de fosforescência de cristais de benzofenona (BZP) e benzofenona incluída em canais de silicalite obtidos à temperatura ambiente e com resolução temporal (igual nos dois espectros) na gama da dezena de microsegundo.

É manifesta a redução dos processos bimoleculares no caso da inclusão em silicalite. Um só sistema permite em simultâneo a obtenção de informação espectroscópica e cinética rigorosa com resolução temporal na gama do nanosegundo ao segundo e na gama espectral do UV-Vis-IVP.

\subsection{A fotólise por impulso de laser em modo de reflectância difusa.}

No início dos anos 80, F. Wilkinson e colaboradores conseguiram demonstrar que a técnica de fotólise por impulso de laser podia também ser aplicada a amostras opacas [1, 13, 20], permitindo assim a realização de um considerável número de estudos fotoquímicos em sistemas heterogéneos, muitos dos quais são opacos. Exemplos disso, as reacções fotoquímicas em espaços confinados, os estudos de moléculas orgânicas adsorvidas ou incluídas em superfícies com acção catalítica, estudos de corantes adsorvidos ou covalentemente ligados a fibras naturais e sintéticas, entre muitos outros. 
Tudo indica que a reflectância difusa de laser venha a ter, no estudo de reacções fotoquímicas em meio heterogéneo, um papel pelo menos tão importante como o que a fotólise em modo de transmissão tem tido para o estudo de reacções fotoquímicas em meio homogéneo.

A técnica baseia-se no estudo das modificações introduzidas pela absorção dos transientes gerados por um impulso de um laser na luz analisadora detectada em modo de reflectância difusa.

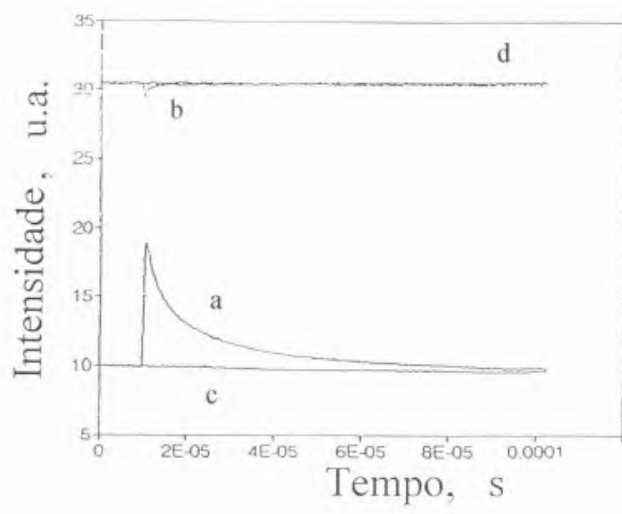

Fig. 12 - a) Absorção transiente de cristais de BZP; b) emissão transiente; c) linha de base; d) linha de topo.

O equipamento usado é idêntico ao dos estudos em transmissão, mas agora utiliza-se uma geometria de reflexão, encontrando-se a luz analisadora e a luz detectada do mesmo lado da amostra. Tal como na fotólise de relâmpago convencional os transientes agora obtidos são espectros de diferença, isto é, a absorção determinada experimentalmente reflecte a diferença de absorção no estado excitado e no estado fundamental para uma dada espécie, a cada comprimento de onda analisado, que depende dos coeficientes de extinção molar do estado excitado e do estado fundamental. É, em muitos casos, importante a correcção da emissão (obtida pelo disparo exclusivo do laser) que aparece de modo subtractivo relativamente ao transiente de absorção.

Para além do desenvolvimento da técnica de fotólise por impulso de laser em modo de reflectância difusa na gama temporal do nanosegundo ao segundo $[1,13,20]$, Wilkinson et al foram os primeiros autores a publicar espectros de absorção transiente de materiais opacos no domínio temporal do picosegundo [51].

Na fotólise por impulso de laser em modo de reflectância difusa, os cromóforos excitados após o disparo do laser estão normalmente distribuídos de um modo homogéneo. Tratamentos teóricos (Kessler e colab. [13] e Oelkrug e colab. [52]) mostraram que existem dois tipos limite de perfil de concentração produzidos, nomeadamente um que decresce exponencialmente em função da profundidade de penetração da radiação incidente e outro perfil homogéneo, como se mostra na Figura 13.

Este último caso encontra-se para grandes fluências do laser (em moles de fotões por $\mathrm{cm}^{2}$ ) e pequenas concentrações de espécies absorvedoras no estado fundamental (curva 4) [20]. Há, neste caso, uma conversão total do estado fundamental $\mathrm{em}$ transiente até uma certa profundidade abaixo da superfície irradiada.

Para baixas percentagens de conversão (altas concentrações de absorvedores no estado fundamental, baixas fluências de laser) a concentração de transientes decresce exponencialmente (curva 1). Nestas condições, uma representação de $\Delta \mathrm{R}_{\mathrm{T}}$ em função do tempo é uma medida da concentração do transiente para amostras pouco concentradas.

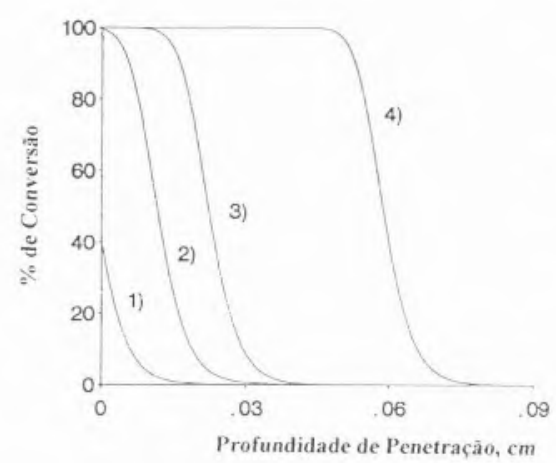

Fig. 13 - Perfis de concentração da espécie excitada em função da profundidade de penetração da radiação de excitação laser.
$\Delta \mathrm{R}_{\mathrm{T}}(\mathrm{t})=\left[1-\mathrm{R}_{\mathrm{T}}(\mathrm{t})\right]=\left[\mathrm{R}_{\mathrm{B}}-\mathrm{R}(\mathrm{t})\right] / \mathrm{R}_{\mathrm{B}}$

em que $R_{B}$ é a reflectância do substrato antes do disparo do laser e $\mathrm{R}(\mathrm{t})$ é a reflectância no instante $t$ após a excitação.

Para o caso de amostras mais concentradas, a variação da função de remissão, antes e depois do disparo do laser, é dada pela aplicação da função de remissão

$$
\Delta F[R(t)]=F[R(t)]-F\left(R_{B}\right)
$$

e como $\mathrm{K}(\mathrm{t})=\mathrm{F}[\mathrm{R}(\mathrm{t})] \mathrm{S}=$

$=\mathrm{K}_{\mathrm{B}}+2 \varepsilon_{\mathrm{G}} \mathrm{C}_{\mathrm{G}}+2 * \mathrm{C}^{*}$.

$\mathrm{K}(0)=\mathrm{F}\left(\mathrm{R}_{\mathrm{B}}\right) \mathrm{S}=$

$=\mathrm{K}_{\mathrm{B}}+2 \varepsilon_{\mathrm{G}} \mathrm{C}_{0} \mathrm{eC}_{0}=\mathrm{C}_{\mathrm{G}}+\mathrm{C}^{*}$

em que $\mathrm{G}$ representa o estado fundamental, $K_{B}$ o coeficiente de absorção do substrato e o asterisco designa o estado excitado, vem imediatamente

$\Delta F\left[(R(t)]=2\left(\varepsilon^{*}-\varepsilon_{G}\right) C^{*} / S\right.$

o que justifica o aparecimento de pontos isosbésticos nos espectros de absorção transiente.

O decaimento apresentado na Figura 12 é da benzofenona (cristais) e diz respeito a um dado comprimento de onda de análise. Considerando todos os comprimentos de onda onde a espécie excitada absorve e escolhendo tempos de análise na curva de decaimento apropriados, podem construir-se espectros de absorção tripleto-tripleto como o da Figura 14, referente a cristais de benzofenona que nos dão, em simultâneo, informação espectroscópica e cinética das amostras opacas.

É evidente que o traçado de espectros resolvidos no tempo como os apresentados na figura acima permitem o estudo de reacções químicas em superfícies, desde que a escolha das escalas temporais seja adequada.

No caso da Figura 14 apresentase a absorção tripleto-tripleto de microcristais da benzofenona obtida à temperatura ambiente, publicada pela primeira vez por Wilkinson e colaboradores em 1984 [13]. Vê-se claramente pelo espectro apresentado que o decaimento inicial é mais 


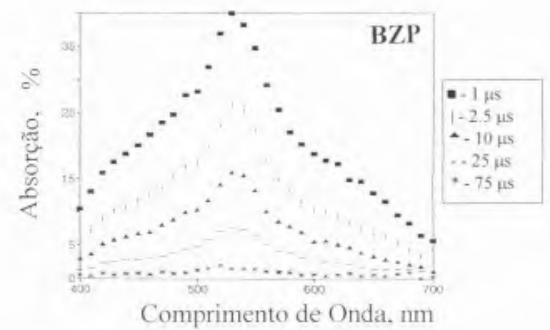

Fig. 14 - Espectro de absorção resolvido no tempo de cristais de BZP.

rápido que a tempos longos, ocorrendo a desexcitação total na casa das dezenas de microsegundo. A cinética é mista de $1^{a}$ e $2^{a}$ ordem. com máximo de ảbsorção a cerca de $540 \mathrm{~nm}$. A emissão de fosforescência, também à temperatura ambiente, evidencia igual cinética de decaimento.

Após o disparo do laser, o transiente assim gerado decai. Considerando um processo unimolecular de decaimento, a concentração de espécie excitada decai exponencialmente de acordo com

$C^{*}(t)=C^{*}(t=0) \exp \left(-k_{1} t\right)$

pelo que, usando pequenas intensidades de excitação, $\left[1-\mathrm{R}_{\mathrm{T}}(\mathrm{t}=0)\right]$ $\leq 0.10$ e a concentração de transientes é proporcional a $\left(1-\mathrm{R}_{\mathrm{T}}\right)$. Então

$\ln \left[1-R_{T}(t)\right]=\ln \left[1-R_{T}(t=0)\right]-k_{1} t(18)$

O uso de altas intensidades de excitação gera camadas opticamente densas de transientes homogeneamente distribuídos, pelo que é necessário agora usar a função de Kubelka-Munk para analisar o decaimento, e a equação (6) transforma-se em

$\ln \left\{\mathrm{F}[\mathrm{R}(\mathrm{t})]-\mathrm{F}\left(\mathrm{R}_{\mathrm{B}}\right)\right\}=$

$=\ln \left\{F[R(t=0)]-F\left(R_{B}\right)\right\}-k_{1} t$

equação usualmente utilizada para qualquer análise primária de dados, que prevê uma relação linear de In $\left\{F[R(t)]-F\left(R_{B}\right)\right\}$ com o tempo, a partir da qual se pode determinar $\mathrm{k}_{1}$. Para a análise de casos mais complexos usa-se igualmente $\left[1-\mathrm{R}_{\mathrm{T}}(\mathrm{t})\right]$ ou $F[R(t)]$ consoante os perfis de con- centração específicos, e a cinética de decaimento em questão [52, 30a, 53].

\subsection{Outras técnicas para estudos de superfícies.}

Já referimos no parágrafo 1 algumas das técnicas que têm sido usadas por numerosos autores para estudos de fotoquímica em superfícies.

Sublinhamos aqui que a espectroscopia de fotoelectrão de raios $X$ (XPS) é uma muito importante técnica de caracterização de superfícies pois analisa as primeira 10 a $20 \mathrm{ca}$ madas atómicas, fornecendo informação sobre a composição e concentração elementares, bem como quanto a interacções intermoleculares sonda-superfície. Recentemente [36, 28 ] esta técnica permitiu obter informações decisivas relativamente a cianinas e rodaminas fisicamente e/ou covalentemente ligadas a celulose.

De igual modo o infravermelho (IV) com transformada de Fourier (FTIR) e em especial a absorção de IV em modo de reflectância difusa para o estudo de superfícies opacas que dispersam a radiação incidente (DRIFT), revelou-se da maior importância para o estudo das interacções específicas de vários cromóforos no seio de diferentes substratos [54, 30b, 30f]. A extensão desta técnica à absorção resolvida no tempo (fotólise por impulso de laser com detecção no IV) virá a ter um papel de grande relevo a curto prazo na fotoquímica de superfícies [55, 54], nomeadamente no esclarecimento de mecanismos reaccionais.

É de referir ainda estudos em superfícies usando a ressonância magnética nuclear para sólidos, e as técnicas de espectroscopia Raman.

\section{ALGUNS EXEMPLOS: FOTOQUÍMICA DE CETONAS, CORANTES E OUTRAS MOLÉCULAS ORGÂNICAS EM SUPERFICIES.}

\subsection{A fotoquímica}

da benzofenona adsorvida em celulose microcristalina, na silicalite e na sílica. Formação de pares de radicais geminados em superfícies.

A aplicação da metodologia respeitante aos espectros de reflectância difusa no estado fundamental apresentada em 3.1 conduziu a resultados algo surpreendentes quando se estudou a BZP adsorvida em celulose microcristalina, usando quer o método de evaporação forçada quer o de equilíbrio [30a e resultados não publicados do autor].

Assim, a utilização de solventes polares próticos e apróticos (metanol, etanol, acetonitrilo, acetona) e até mesmo apolares como o dioxano, induz deslocamentos hipsocrómicos na transição $n \rightarrow \pi^{\star}$ da BZP, relativamente à situação de utilização de solventes como o benzeno, o iso-octano ou o diclorometano onde estas bandas de absorção aparecem deslocadas para o vermelho e apresentando até alguma resolução vibracional. Estes factos decorrem da maior ou menor capacidade dos vários solventes usados contribuírem para o inchamento da matriz polimérica [30a, 25b, 26], quebrando as ligações cadeia-cadeia e formando ligações cadeia-solventecadeia. Deste modo a sonda pode penetrar mais ou menos no seio da matriz, ou ficar à sua superfície formando microcristais. A BZP pode ser assim usada como sonda para analisar a capacidade de diferentes solventes para incharem a celulose.

As consequências deste maior ou menor contacto íntimo da BZP com as cadeias celulósicas são também notáveis quanto ao comportamento fotoquímico da sonda. Assim, o espectro de absorção resolvido no tempo do sistema BZP/celulose/diclorometano onde a sonda se depositou à superfície apresenta características quer cinéticas quer espectroscópicas dos microcristais de BZP, enquanto que no caso do etanol ou de outros solventes que incham a celulose, assiste-se à formação do radical cetilo da BZP, com um tempo de vida bem mais longo do que o tripleto da BZP [30a, 34], e com um máximo de absorção transiente a cerca de $560 \mathrm{~nm}$. 
Outro exemplo de fotoquímica da benzofenona no seio da celulose microcristalina é dado pela formação de pares geminados de radicais formados por co-adsorção de BZP e 2,4,6-trimetilfenol, também no seio da celulose microcristalina (ver Figura 15).

O espectro de absorção medido logo após o disparo do laser evidencia claramente a formação quer de $\mathrm{BZPH}^{\bullet}$, quer do radical fenóxido $\mathrm{PO} \cdot$ assim formado [53a]. O estudo da cinética da recombinação geminada destes radicais evidencia quer componentes curtas $(\sim 10 \mu \mathrm{s})$, quer longas $(\sim 100 \mu \mathrm{s})$, com um padrão de multi-exponencialidade que reflecte a heterogeneidade e locais de adsorção experimentados pelo par radicalar. A celulose assegura uma baixa mobilidade de ambos os radicais, que estão essencialmente a formar um par de contacto. Não se detectou neste caso efeito da aplicação de um campo magnético exterior.

Outro exemplo interessante da influência do adsorvente é dado pela inclusão de sondas como a $\beta$-fenilpropiofenona ( $\beta$-PP) nos canais hidrofóbicos da silicalite. É conhecido da literatura que esta molécula em solução pode apresentar diferentes conformações. Acontece que naquelas em que o grupo fenilo se aproxima do carbonilo, ocorre rapidamente a desexcitação intramolecular do tripleto excitado desta molécula [12],

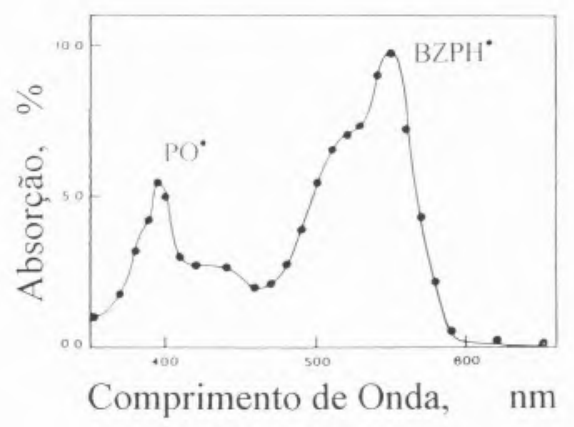

$$
\mathrm{BZP} \longrightarrow{ }^{3} \mathrm{BZP} \stackrel{\mathrm{POH}}{\longrightarrow}\left[\mathrm{BZPH}^{\circ}, \mathrm{PO}^{\circ}\right]
$$

Fig. 15 - Recombinação geminada de pares de radicais. de tal modo que o tempo de vida em solução é de cerca de um nanossegundo. A inclusão da molécula nos canais de silicalite permite ao carbonilo excitado viver durante alguns microsegundos [30d], como o mostram os espectros de emissão resolvidos no tempo apresentados na Figura 16.

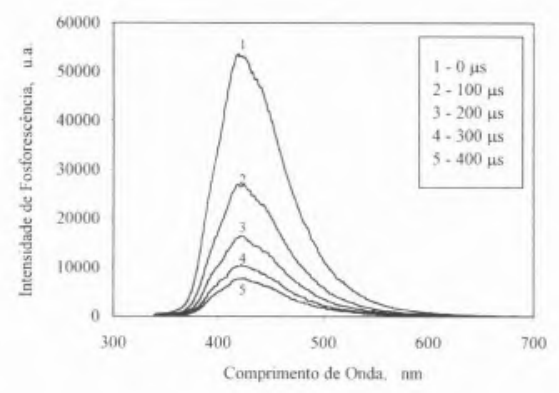

Fig. 16 - Espectro de fosforescência à temperatura ambiente da $\beta$-fenilpropiofenona ( $\beta$-PP) incluída nos canais de silicalite.

Saliente-se que esta emissão de fosforescência foi obtida à temperatura ambiente e que as amostras não foram sequer desoxigenadas. A difusão do oxigénio no seio dos canais do zeólito já ocupados pela $\beta$-PP é de tal modo reduzida que este não extingue os tripletos excitados da $\beta$-PP.

A inclusão da $\beta$-PP no seio da celulose microcristalina permitiu de igual modo detectar o cetilo desta cetona neste substrato, contrastando com a sua inércia fotoquímica em solução [30e].

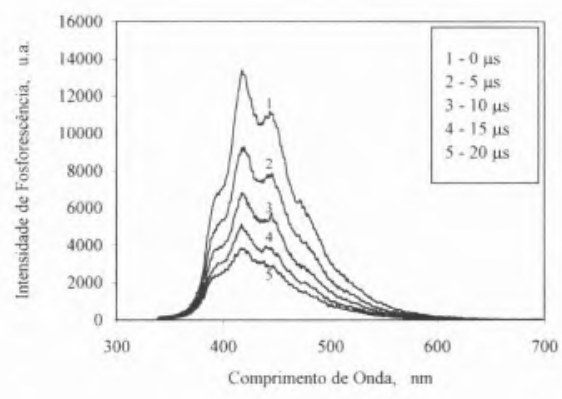

Fig. 17 - Espectro de fosforescência à temperatura ambiente da acetofenona incluída nos canais de silicalite.
A Figura 17 apresenta a emissão de fosforescência da acetofenona incluída nos canais de silicalite, também obtida à temperatura ambiente. O menor tempo de vida quando comparado com a $\beta$-PP evidencia menor grau de imobilização desta sonda na silicalite, certamente por razões ligadas ao seu menor volume cinético.

\subsection{Transferência de energia em superfícies: os casos da benzofe- nona / 2-metilnaftaleno, benzo- fenona / oxazina e acetonaftona / laranja de acridina.}

Daremos agora alguns exemplos de estudos de absorção tripleto-tripleto em superfícies relevantes, começando pelo primeiro estudo de transferência de energia realizado com o auxílio da fotólise por impulso de laser em modo de reflectância difusa: transferência tripleto-tripleto da benzofenona (BZP) para o naftaleno (N) [11], co-adsorvidos em sílicas de diferentes porosidades. Assim, Turro e colab. observaram o aparecimento da absorção do tripleto do naftaleno $(\mathrm{N})$ com um máximo a cerca de $400 \mathrm{~nm}$, após excitação selectiva da BZP a $355 \mathrm{~nm}$. De igual modo os autores apresentam a espectro de absorção $\mathrm{T}_{1} \rightarrow \mathrm{T}_{\mathrm{n}}$ da BZP na ausência de N. O aumento das constantes de velocidade de decaimento da BZP determinadas na presença de sucessivos aumentos da concentração de N, evidenciando a natureza dinâmica do processo de extinção da BZP pelo $\mathrm{N}$ na superfície da sílica. Os autores apresentam também estudos cinéticos para duas sílicas, de $255 \AA$ e $95 \AA$ de poro, que aparentam maior eficiência de extinção na sílica de maior porosidade. Usando, no entanto, concentrações em termos de moles de sonda por unidade de área superficial (determinada por medidas de $\mathrm{N}_{2}$-BET), aparentemente as constantes de velocidade dos processos de extinção são semelhantes [11].

Estudos semelhantes foram realizados por nós para os sistemas benzofenona/1-metilnaftaleno (BZP/ 
(1MN) [56], benzofenona / oxazina 725 (BZP/OXZ) [32] e acetonaftona / laranja de acridina (ACN/LA) [33], todos co-adsorvidos em celulose. Mostram-se nas Figuras 18 alguns desses resultados:

O sistema BZP/1MN foi objecto de estudo quer em solução (acetonitrilo), quer com o doador e aceitante co-adsorvidos em sílica, e na celulose microcristalina [56]. Em todos os casos, mantendo constante a con-

\section{BZP / 1MN}
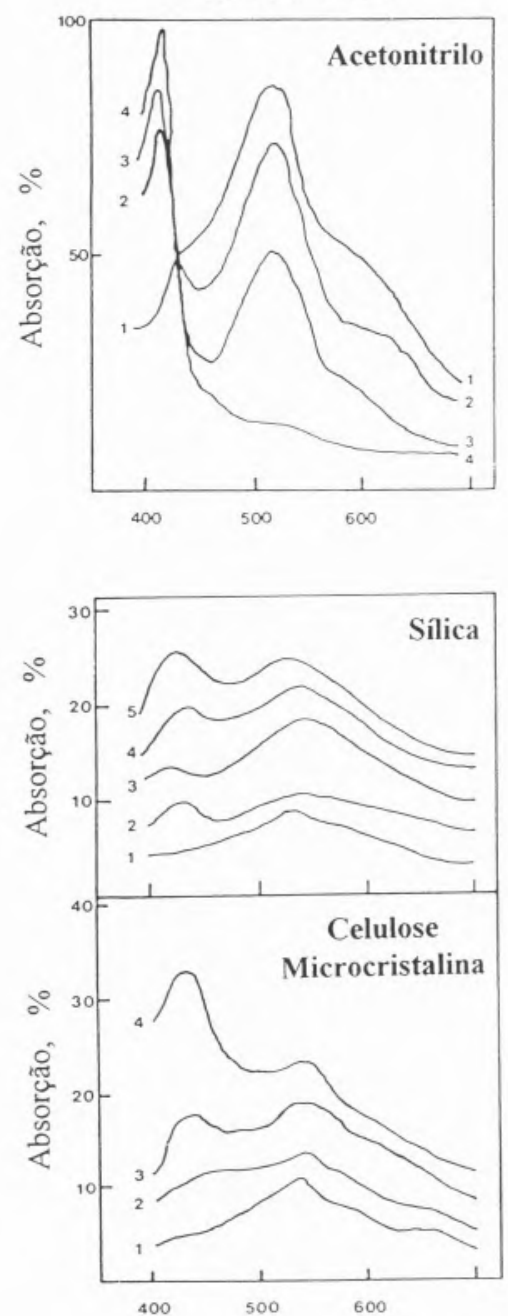

Comprimento de Onda, $\mathrm{nm}$

Fig. 18 - Transferência de energia BZP/1-Me-Naftaleno em acetonitrilo, em superfície de sílica de $150 \AA$ A de poro e incluída no seio da celulose microcristalina. centração da BZP e aumentando a concentração de $1 \mathrm{MN}$ evidencia-se claramente a formação da banda de absorção transiente $\mathrm{T}_{1} \rightarrow \mathrm{T}_{3}$ situada a cerca de $420 \mathrm{~nm}$, característica do tripleto do derivado de naftaleno. Em solução o processo de transferência de energia é controlado por difusão. Nas superfícies em questão é essencialmente estático.

A quantificação rigorosa da absorção directa da radiação de excitação pelo soluto (curvas A e B da figura 19) e ainda da transferência não radiativa (curva $\mathrm{C}$ ), foi feita pela primeira vez nos estudos dos sistemas BZP/OXZ [32] e ACN/LA [33].

\section{BZP / OXZ725}
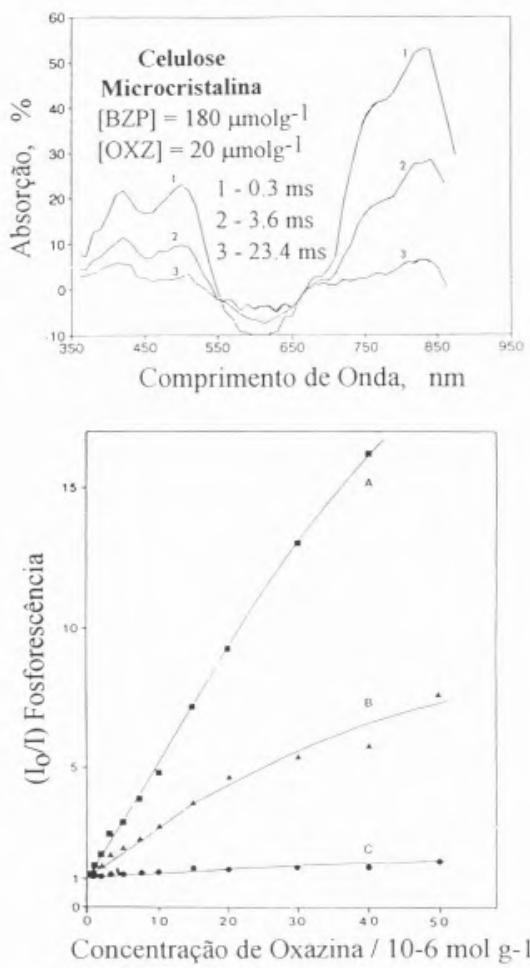

Fig. 19 - Transferência de energia BZP/Oxazina 725 no seio de celulose microcristalina.
Mostrou-se que um modelo simples de extinção estática, em que existem dois tipos de BZPs, as que têm um vizinho aceitante e sofrem extinção e aquelas que não têm vizinho e não sofrem extinção, é suficiente para interpretar os resultados experimentais.

Saliente-se que quer a laranja de acridina quer a oxazina 725 apresentam fluorescência com atraso, no primeiro caso por excitação directa e sensibilizada, no segundo caso apenas por sensibilização [33, 32].

Com bases em todos estes estudos estabeleceu-se inequivocamente a natureza estática do processo de transferência de energia no seio da celulose. De igual modo se evidenciou a ausência de efeito de extinção do oxigénio nos tripletos do doador directamente excitado, ou nos tripletos dos aceitantes gerados pelos mecanismos de sensibilização.

\subsection{A determinação de rendimentos quânticos de emissão em superfícies. A influência da agregação. Aplicação a corantes.}

A determinação quantitativa rigorosa do rendimento quântico de emissão da luminescência de corantes ou outras moléculas adsorvidas em substratos sólidos é um problema importante, embora de abordagem difícil. Obriga à determinação da luz absorvida pela amostra ao comprimento de onda de excitação, ao uso de substâncias de referência apropriadas, a um estudo rigoroso da agregação da sonda que pode afectar profundamente a emissão, ao conhecimento da extensão da auto-absorção e ainda à possível existência de efeitos de extinção por concentração.

O problema foi por nós abordado através de um estudo detalhado que envolveu as rodaminas 101 e $6 \mathrm{G}$ adsorvidas em celulose microcristalina que podem ser usadas como referências [27], e posteriormente aplicado a outros corantes e superfícies $[57,28,29,35,36]$.

Na Figura 20 mostram-se as rectas de calibração por nós obtidas e 

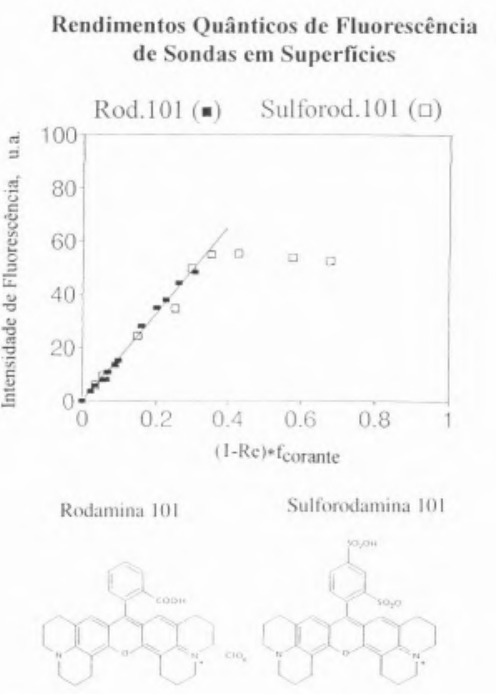

Solução

$I_{\mathrm{F}}\left(\lambda_{\mathrm{em}}\right)=\mathrm{C} \quad \phi_{\mathrm{F}} \quad \mathrm{I}_{\mathrm{O}}\left(\lambda_{\text {exc }}\right)(1-10-\varepsilon \mathrm{cl})$

$\phi_{\mathrm{F}}^{\mathrm{u}}=\phi_{\mathrm{F}}^{\mathrm{s}} \frac{\mathrm{I}_{\mathrm{F}}^{\mathrm{u}} \mathrm{I}_{\mathrm{o}}^{\mathrm{s}} \lambda(\mathrm{exc} \cdot)(\varepsilon \mathrm{cl})^{\mathrm{s}}}{\mathrm{I}_{\mathrm{F}}^{\mathrm{s}}}$

\section{Sólidos}

$\operatorname{IF}\left(\lambda_{\text {em. }}\right)=C_{\phi} \quad I_{\mathrm{O}}\left(\lambda_{\text {exc. }}\right)(1-R) f$

$\phi_{\mathrm{F}}^{\mathrm{u}}=\phi_{\mathrm{F}}^{\mathrm{s}} \frac{\mathrm{I}_{\mathrm{F}}^{\mathrm{u}}}{\mathrm{I}_{\mathrm{F}}^{\mathrm{s}}} \frac{\left(1-\mathrm{R}^{\mathrm{s}}\right) \mathrm{f}^{\mathrm{s}}}{\left(1-\mathrm{R}^{\mathrm{u}}\right) \mathrm{f}^{\mathrm{s}} \lambda\left(\mathrm{I}_{\mathrm{o}}^{\mathrm{u}} \lambda(\text { exc. })\right.}$

$\mathrm{R}=$ Reflectância

$f=\frac{F(R)_{\text {Corante }}}{F(R)_{\text {Total }}}$

Fig. 20 - Determinação do rendimento quântico da emissão de luminescência de moléculas adsorvidas em substratos sólidos.

correntemente usadas para a determinação de rendimentos quânticos de luminescência de sondas adsorvidas em sólidos em pó (amostras opticamente densas). Salienta-se a necessidade de conhecer, para cada

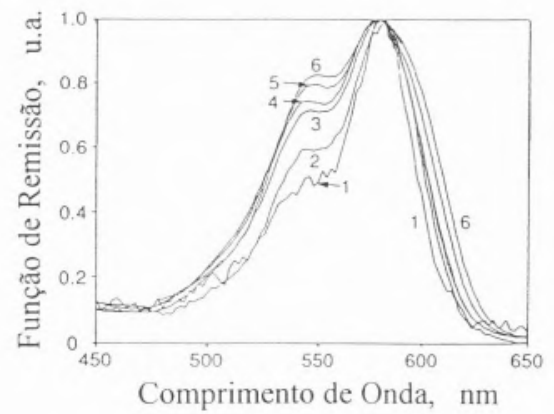

\section{Rodamina 101}

$1-0.015 \mu \mathrm{mol} \mathrm{g-1}$

$2-0.085 \mu \mathrm{mol} \mathrm{g}-1$

$3-0.43 \mu \mathrm{mol} \mathrm{g-1}$

$4-0.61 \mu \mathrm{mol} \mathrm{g}^{-1}$

$5-1.2 \mu \mathrm{mol} \mathrm{g}^{-1}$

$6-5.8 \mu \mathrm{mol} \mathrm{g}^{-1}$
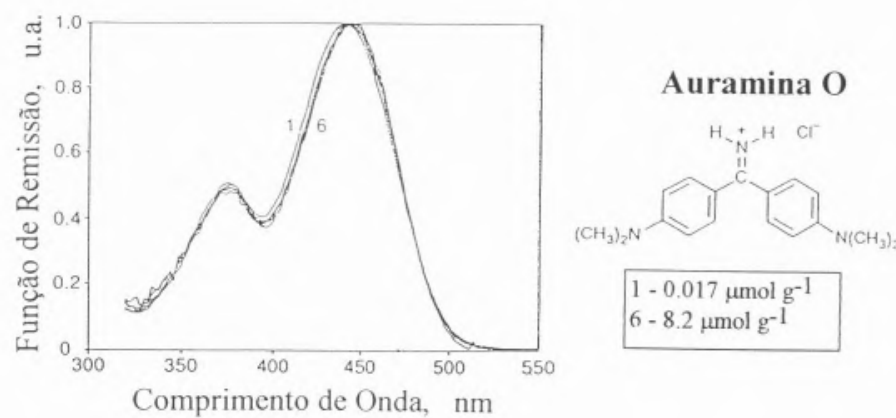

Fig. 21 - Agregação de corantes adsorvidos em celulose microcristalina.

aparelhagem, o perfil de energias de excitação como se demostrou anteriormente [58].

Sublinha-se também que corantes com rendimentos quânticos de emissão de fluorescência muito baixos em solução, como certas cianinas ou a auramina $\mathrm{O}$, chegam a ter aumentos de rendimentos quânticos de três e quatro ordens de grandeza, à temperatura ambiente, quando a sonda é armadilhada no seio da celulose microcristalina. A rigidificação estrutural imposta pelo hospedeiro conduz a uma drástica redução dos mecanismos de desexcitação não radiativos.

Deste modo verificou-se também que pequenas quantidades residuais de humidade na amostra podem ter um efeito significativo no rendimento quântico de emissão de fluorescência [29, 27b].

Nalguns corantes a agregação é particularmente significativa, como no caso da rodamina 101 (depositada a partir de etanol), apresentado na Figura 21, enquanto que outros corantes como a auramina $\mathrm{O}$, também depositada a partir de etanol, quase não agregam na mesma gama de concentrações [27b].

\subsection{A fotoquímica e fotofísica} de corantes adsorvidos em celulose microcristalina e sílicas de diferentes porosidades.

\section{Cianinas}

Os estudos fotoquímicos e fotofísicos de cianinas são actualmente um domínio de investigação relevante devido à importância económica destes corantes na fotografia a preto e branco e a cores, como corantes laser, como potenciais sensibilizadores na fototerapia dinâmica do cancro e ainda pela sua aplicação em dispositivos de armazenamento óptico de informação [35].

A agregação de cianinas em substratos electronicamente inertes está exemplificada na Figura 22, onde se apresentam os espectros de reflectância difusa de algumas tiacianinas, nomeadamente a $3,3^{\prime}$-dietiltiacarbocianina (TCC) e a 3,3'-dietil-9-metiltiacarbocianina (9-MeTCC). 

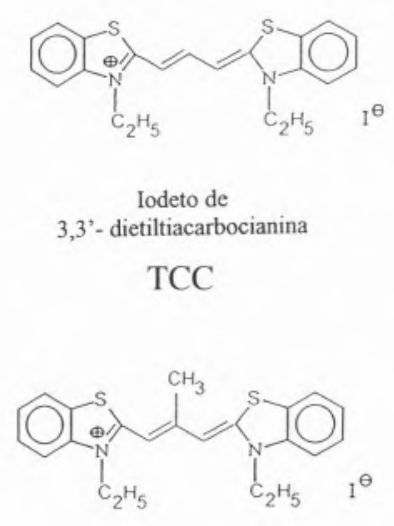

Iodeto de

3,3'- dietil-9-metiltiacarbocianina

$$
9 \text { - Me - TCC }
$$

Evidencia-se claramente no $2^{\circ}$ caso quer a formação de agregados em sanduíche (agregados $\mathrm{H}$ ), com absorção a maiores energias que o monómero do corante, quer também a formação de agregados cabeçacauda (agregados J) na gama de con-
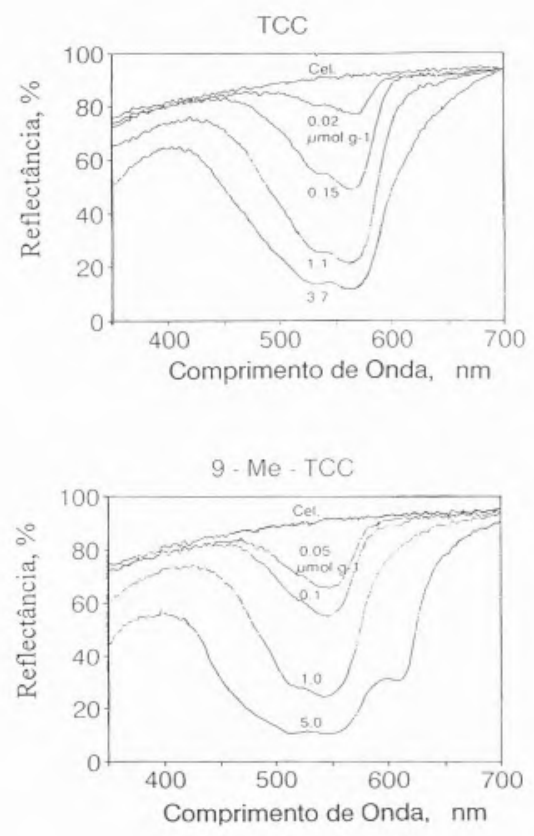

Fig. 22 - Espectros de reflectância difusa de duas tiacarbocianinas em função da concentração dos corantes adsorvidos em celulose microcristalina.
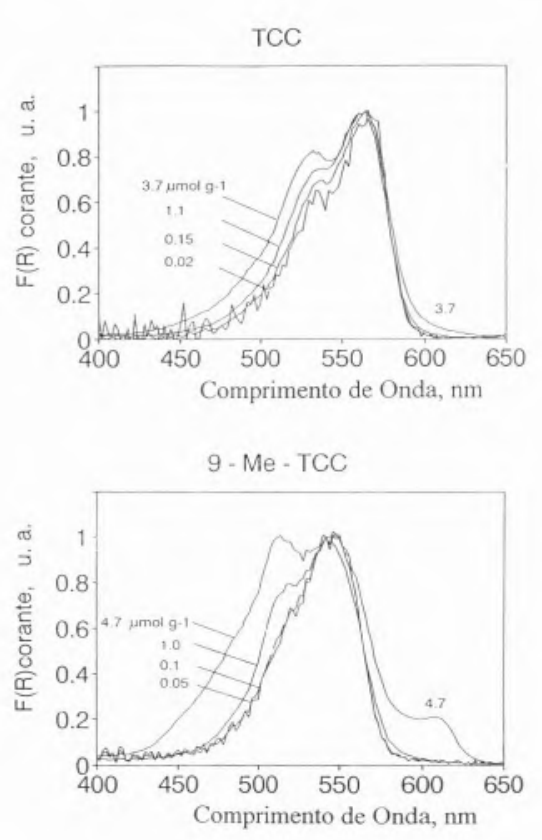

Fig. 23 - Função de remissão das mesmas amostras.

centrações de 5 a $15 \mu$ mol por grama de celulose, cuja absorção se situa a cerca de $610 \mathrm{~nm}$. A 3,3'-dietiltiacarbocianina já não evidencia a formação de agregados J, mostrando assim que pequenas modificações estruturais podem conduzir a alterações significativas na agregação do corante.

As funções de Kubelka-Munk apresentadas na Figura 23 mostram, de igual modo, que a introdução de um grupo metilo na posição 9 da carbocianina favorece a agregação $\mathrm{J}$. O estudo detalhado da influência da concentração e consequentemente da agregação na emissão de fluorescência destas moléculas é sintetizado nas Figuras 24 e 25.

Assim, para pequenas concentrações de corante, nomeadamente até cerca de 0.5 a $1.0 \mu \mathrm{mol}$ de corante por grama de substrato, a intensidade de emissão de fluorescência cresce com a luz absorvida pela amostra, ou melhor, com a fracção dessa luz que é absorvida pelo corante na amostra, pois o substrato também frequentemente o faz ao comprimento de onda de excitação. Ao percorrermos a gama de concentra- ções de 1 a $50 \mu \mathrm{mol} \mathrm{g}^{-1}$ detectamos um forte decréscimo da intensidade de emissão de fluorescência uma vez que parte dos fotões de excitação são absorvidos pelas formas agregadas do corante $(\mathrm{H} \mathrm{e} \mathrm{J})$, das quais não se detectou emissão. Teoricamente é possível a extinção da fluorescência dos monómeros pelos agregados $\mathrm{H}$ e J, dado que existe sobreposição espectral da emissão do primeiro pelos segundos. No entanto, noutros casos $[32,56]$ em que foi possível determinar os coeficientes de extinção molar do monómero e do dímero no estado fundamental, a simples consideração das fracções de radiação de radiação absorvidas pelo monómeros (emissivos) e agregados (não emissivos) foi suficiente para a interpretação dos resultados experimentais.

A TCC e a 9-Me-TCC, que em solução etanólica apresentam $\phi_{\mathrm{F}}$ da ordem de grandeza de 0.05 , quando armadilhadas no seio da celulose aumentam a sua emissão de fluorescência para $\phi_{\mathrm{F}}$ cerca de 0.95 . É conhe-
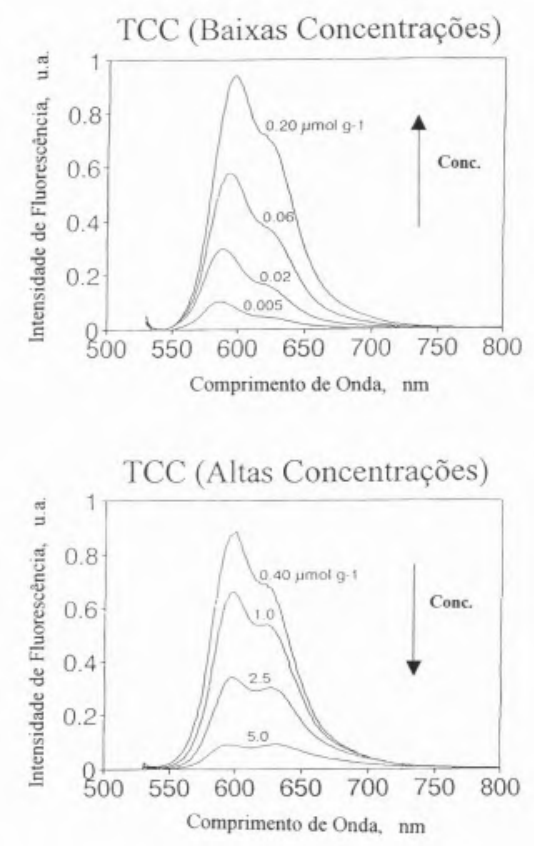

Fig. 24 - Espectros de emissão de fluorescência da TCC em baixas e altas concentrações da sonda na celulose microcristalina. 

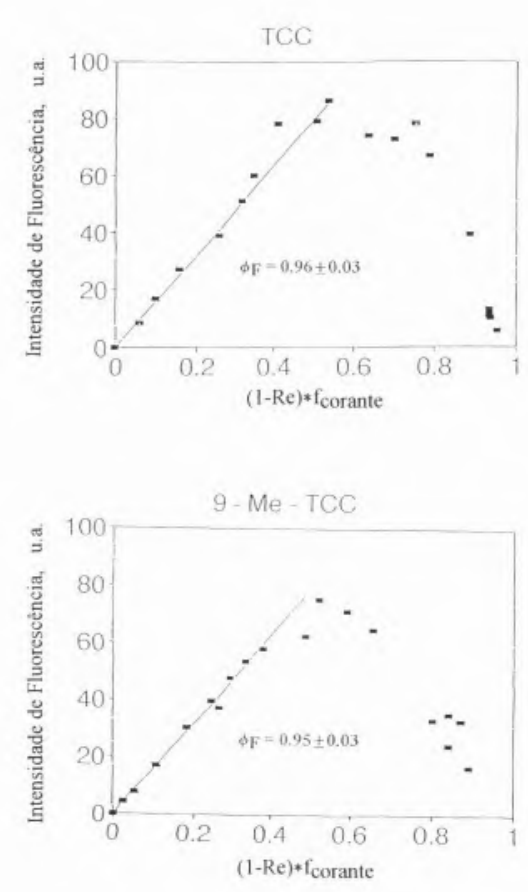

Fig. 25 - Rendimentos quânticos da emissão de fluorescência de TCC e 9-Me-TCC adsorvidas em celulose microcristalina.

cido que a desexcitação não-radiativa de $\mathrm{S}_{1}$ dos corantes polimetínicos em solução à temperatura ambiente é predominantemente a isomerização trans-cis. Nas cianinas, na forma monomérica e na ausência de impedimentos estereoquímicos, quer os rendimentos quânticos de fluorescência, quer os rendimentos de cruzamento intersistemas são geralmente muito baixos. Quer a TCC, quer a 9-Me-TCC quando no seio da celulose microcristalina apresentam rendimentos de fluorescência quase unitários, como se mostra na Figura 25.

Contrastando com os resultados em estado estacionário algumas amostras destas cianinas apresentam, quando excitadas com lasers de fluência elevada, uma segunda emissão a comprimentos de onda maiores que o respectivo monómero. As Figuras 26 e 27 apresentam esta nova emissão como função da fluência do laser e da concentração da sonda adsorvida para as duas tiacarbocianinas citadas.
Salienta-se que a cianina que forma agregados J não apresenta a nova emissão ou pelo menos ela é extremamente reduzida. O fenómeno ocorre na gama temporal do nanosegundo, ou seja, tem a sua origem nos monómeros do corante.

De igual modo esta nova emissão foi detectada em 2,2'-cianinas e oxacianinas $[35,36]$. Os estudos de energia revelaram uma dependência supralinear da energia.

Do conjunto de estudos efectuados concluiu-se que a nova emissão tem origem num fotoisómero criado pela absorção do primeiro fotão, sendo o segundo fotão absorvido por esta espécie, assim criada, o responsável pela nova emissão [35a].

Estudos recentes de picosegundo com laser de elevada fluência ("pump and probe experiments") confirmaram esta interpretação e permitiram determinar o tempo de vida da nova espécie nalguns casos [35c, 35e].
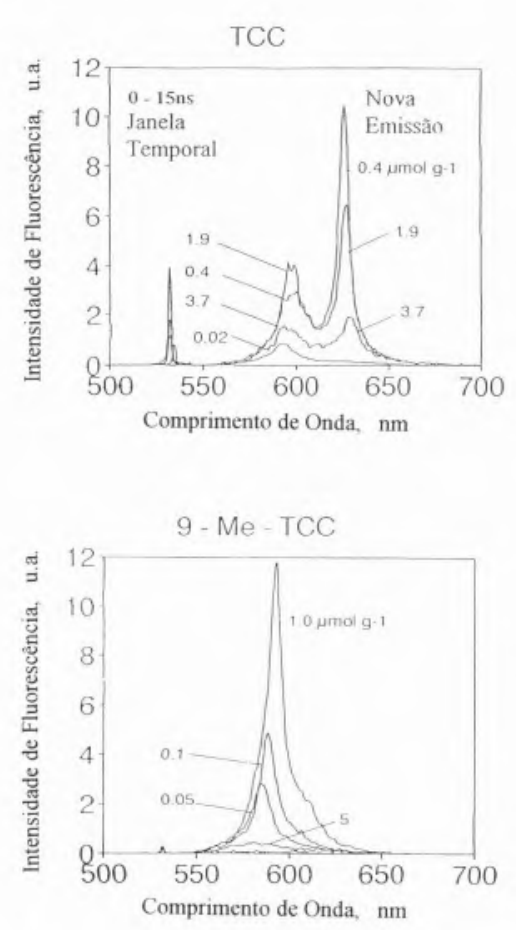

Fig. 26 - Emissão induzida por laser da TCC e da 9-Me-TCC em função da concentração da sonda.
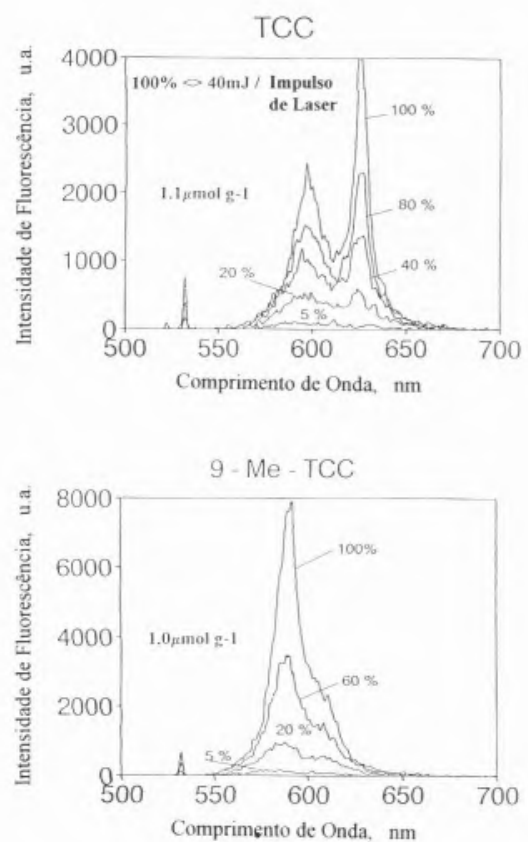

Fig. 27 - Emissão induzida por laser da TCC e da 9-Me-TCC em função da energia do laser.

\section{Rodaminas}

$\mathrm{O}$ estudo iniciado com as rodaminas 101 e $6 \mathrm{G}$ adsorvidas em celulose microcristalina foi estendido a outras rodaminas zwiteriónicas (sulforodamina 101 e sulforodamina B) e também a outras rodaminas não rigidificadas (rodaminas B e 3B). Apenas a sulforodamina 101 apresenta $\phi_{\mathrm{F}}$ unitário, sendo de sublinhar que a presença de humidade nas amostras diminui o $\phi_{\mathrm{F}}$ em todos estes casos [29].

A sulforodamina 101 e a rodamina $6 \mathrm{G}$ foram objecto de um estudo especial, adsorvidas na superfície de sílicas de diferentes porosidades, nomeadamente $22 \AA, 60 \AA$ e $150 \AA$. Apresentam-se nas Figuras 28 e 29 alguns dos resultados desses estudos:

A forma dos espectros de absorção da rodamina $6 \mathrm{G}$ adsorvida em sílica quase não varia com o aumento da concentração do corante, ao passo que os espectros do estado fundamental da sulforodamina 101 apresentam uma nova banda de absorção deslocada hipsocromicamente relativamente ao monómero. Esta banda, 


\section{Rodamina 6G}
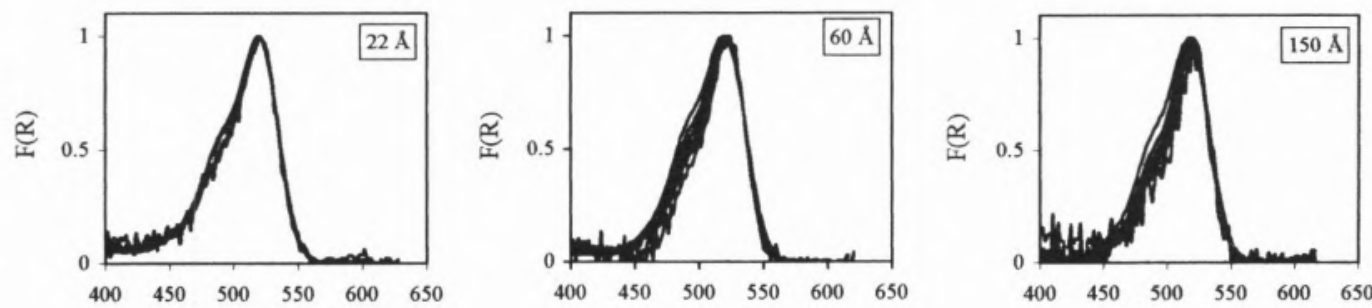

Sulforodamina 101
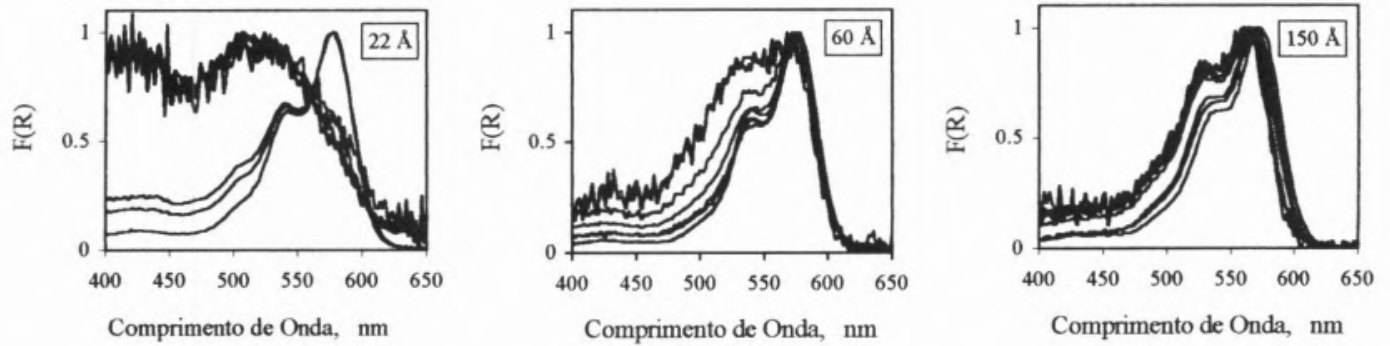

Fig. 28 - Função de remissão de rodaminas adsorvidas em sílica de diferentes porosidades.

intensa para soluções muito diluídas, desaparece à medida que aumentamos a concentração da sonda ou a porosidade da sílica.

Os rendimentos quânticos dos dois corantes apresentam fortes desvios à linearidade (encontrada no caso da adsorção em celulose microcristalina) que varia também com o

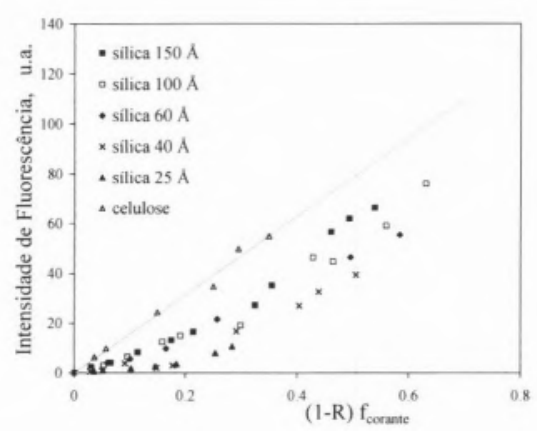

Fig. 29 - Emissão de fluorescência de rodaminas adsorvidas em sílica de diferentes porosidades. poro da sílica e a concentração, como se mostra na Figura 29.

Os resultados apontam para a formação de confórmeros não planares no caso da sulforodamina 101 , formados por forte interacção com a superfície da sílica após activação desta.

\subsection{A fotoquímica de um corante rodamínico ligado covalente- mente à celulose microcristalina.}

Prepararam-se amostras de isotiocianato de rodamina $\mathrm{B}$ adsorvido em celulose microcristalina por dois métodos diferentes: por evaporação de solvente, a partir de soluções etanólicas e aquosas, e ainda a partir de soluções aquosas em equilíbrio com o sólido em pó, seguindo um protocolo industrial que se esquematiza na Figura 30.

Nas amostras tingidas o corante fica ligado covalentemente à cadeia polimérica, do modo que se mostra na mesma figura. Quer as amostras tingidas, quer as amostras depositadas foram lavadas abundantemente, tendo-se verificado em ambos os casos que a quase totalidade do corante reactivo ficou ligado à celulose [28].

Os espectros de reflectância difusa em função da concentração do corante ligado, que se mostram na Figura 31 evidenciam um forte alargamento das bandas de absorção visíveis da rodamina $\mathrm{B}$, mostrando assim em primeiro lugar a heterogeneidade dos locais de adsorção à celulose.

Na Figura 32 compara-se a absorção do monómero do corante em solução etanólica com a absorção no sólido duma amostra tingida e de outra depositada, sendo evidente o forte deslocamento hipsocrómico da tingida, resultante de uma diminuição da conjugação.

Os rendimentos quânticos determinados foram $0.40 \pm 0.03 \mathrm{e}$ 


\section{Isotiocianato da Rodamina B - Corante Reactivo}

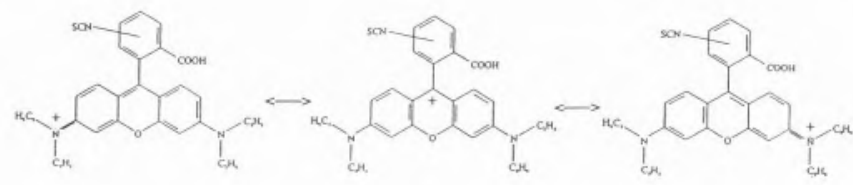

Tingimento da Celulose

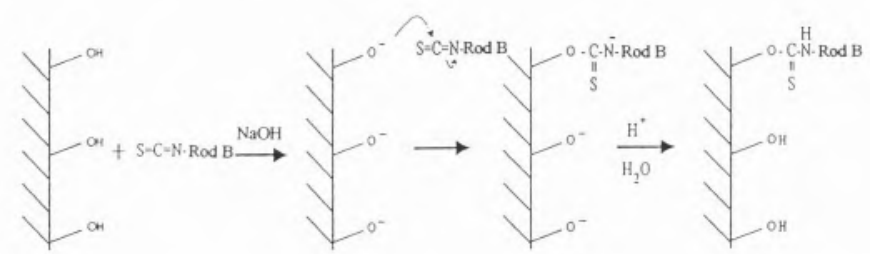

Fig. 30 - Tingimento de celulose com um corante reactivo.

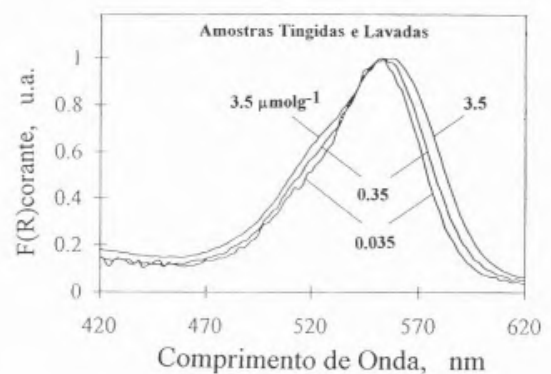

Fig. 31 - Funções de remissão de amostras tingidas e lavadas.

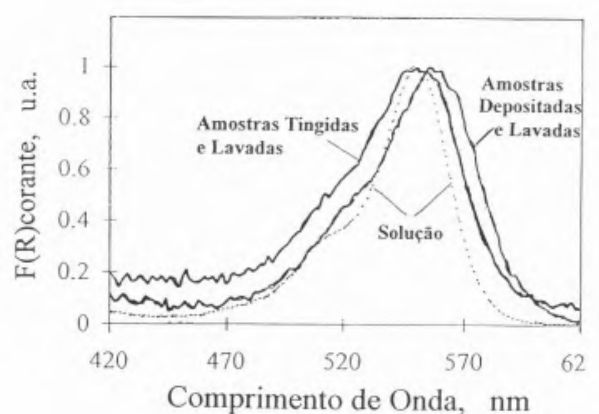

Fig. 32 - Comparação das funções de remissão de amostras tingidas e lavadas e depositadas e lavadas.

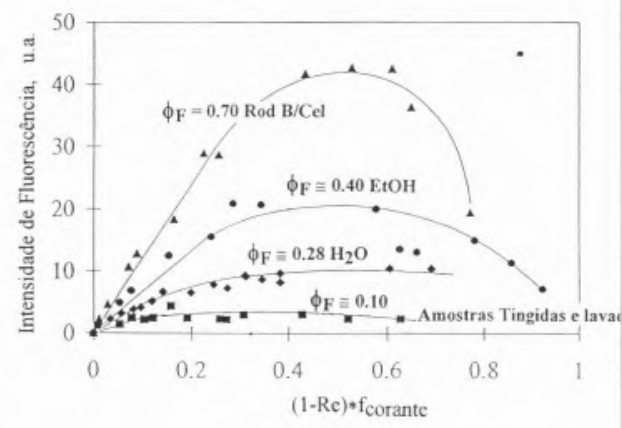

Fig. 33 - Rendimentos quânticos de emissão de fluorescência de amostras tingidas e lavadas e de amostras depositadas e lavadas.

\section{CONCLUSÕES E POSSÍVEIS TRABALHOS FUTUROS}

Apresentaram-se alguns exemplos da aplicação de técnicas de reflectância difusa a sistemas heterogéneos. Os espectros de absorção e emissão resolvidos no tempo assim obtidos proporcionam uma análise espectroscópica e cinética que permite um estudo seguro de muitas reacções fotoquímicas que ocorrem à superfície dos sólidos.

A conjugação da informação obtida a partir de medidas transientes com a obtida no estudo da absorção no estado fundamental (antes e depois da irradiação das amostras sólidas em muitos casos) permite frequentemente obter informações que não estariam acessíveis por nenhuma das técnicas isoladamente.

Os processos fotoquímicos primários podem assim ser estudados em sistemas opacos e heterogéneos com o uso destas técnicas, sem ser necessário recorrer ao uso dos sistemas modelo clássicos ou seja as amostras transparentes em solução.

Prevê-se num futuro a curto prazo desenvolver ou continuar a desenvolver as seguintes linhas de trabalho:

- Estudos de controle de poluentes ambientais, nomeadamente a identificação e quantificação da degradação de HPAs usando as técnicas de absorção e emissão descritas. 
- Estudos de degradação de corantes (nomeadamente corantes reactivos) em celulose, lã e outros polímeros sintéticos, com relevo para o estudo do efeito de oxigénio no seio das fibras.

- Estudo da fotoquímica de cetonas em ambientes confinados, nomeadamente celuloses, ciclodextrinas e zeólitos.

- Estudos de foto-estabilidade de corantes laser.

Sublinha-se também que o cruzamento da informação obtida pela utilização das técnicas de fotoquímica de superfícies descritas no parágrafo 3 com outras técnicas de superfícies como o XPS e o DRIFTS existentes no Laboratório de Técnicas de Superfícies do CQFM se tem revelado particularmente frutuoso na resolução de muitos problemas da Fotoquímica de Superfícies. Nos trabalhos a desenvolver iremos certamente continuar a privilegiar a atitude de usar técnicas que se complementem na clarificação dos sistemas em estudo.

\section{AGRADECIMENTOS}

LFVF agradece às colaboradoras Dra. Anabela Sousa de Oliveira e Enga. Maria João Lemos a ajuda dada na preparação do manuscrito. De igual modo se agradece aos Professores J.C. Netto-Ferreira, A.M. Rego e M.R. Vieira Ferreira as sugestões e apoio dados.

\section{* Centro de Química-Física Molecular, Complexo Interdisciplinar. Instituto Superior Técnico, 1096 Lisboa Codex, Portugal. \\ (e-mail: LFVieiraFerreira@ist.utl.pt)}

Palavras Chave: Fotoquímica de Superfícies, Reflectância Difusa, Luminescência Induzida por Laser, Fotólise por Impulso de Laser, Transferência de Energia, Corantes, Celulose, Sílicas, Silicalite.

\section{BIBLIOGRAFIA}

1. F. Wilkinson, G.P. Kelly - "Diffuse Reflectance Flash Photolysis", in "Handbook of Organic Photochemistry", Ed. J.C. Scaiano, CRC Press, Boca Raton, 1989, Cap. 1, p. 293, e referências aí citadas.
2. a) R.J. Hurtubise - "Phosphorimetry: Theory, Instrumentation and Applications", VCH Publishers, New York, 1990. b) R.J. Hurtubise - "Solid Surface Luminescence Analysis. Theory, Instrumentation and Applications", Marcell Dekker, New York, 1981.

3. a) "Surface Photochemistry" Ed. M. Anpo, Wiley, Baffins Lane, 1996. b) "Photochemistry on Solid Surfaces", Eds. M. Anpo and T. Matsuara, Elsevier, Amsterdam, 1989.

4. C. Bohne, R.W. Redmond, J.C. Scaiano - "The use of Photochemical Techniques in the Study of Organized Assemblies", in "Photochemistry in Organized and constrained Media", Ed. V. Ramamurthy, VCH Publishers, New York, 1991 . Cap. 3, p.79.

5. L.J. Johnston - "Phototransformations of Organic Molecules Adsorbed on Silica and Alumi$n a "$, in "Photochemistry in Microheterogeneous Systems", Ed K. Kalyanasundaram, Academic Press, Orlando, 1987, Cap. 8, p. 359.

6. I.H. de Boer - Z Phys. Chem., Abt. B, 14 (1931) 163

7. C.H. Nikolls, P.A. Leemakers - Adv. Photochem., 8 (1971) 315 e referências aí citadas; L.D. Weis, B.W. Bowen, P.A. Leemakers - J. Am. Chem. Soc, 88 (1966) 3176.

8. P. de Mayo, L.V. Natarajan, W.R. Ware in "Organic Phototransformations in nonhomogeneous Media", Ed. M.A. Fox, ACS Symp. Series, 278 (1984) 1 e referências aí citadas; P. de Mayo Pure Appl. Chem. 54 (1982) 1623. P. de Mayo, L.V. Natarajan, W.R. Ware - Chem. Phys, Lett., 107 (1984) 187; P. de Mayo, L.V. Natarajan, W.R. Ware -J. Phys.Chem., 89 (1985) 3526.

9. D. Oelkrug, M. Plauschinat, R W. Kessler - J. Lumin, 18/19 (1979) 434; R W. Kessler, S. Uhl, W. Honnen, D. Oelkrug - J. Lumin., 24/25 (1981) 551; W. Honnen, G. Krabichler, S. Uhl, D. Oelkrug - J. Phys. Chem., 87 (1983) 4872; K. Kempfer, S. Uhl, D. Oelkrug - J. Mol. Stucture, 114 (1984) 225; D. Oelkrug, W. Flemming, R. Fullerman, R. Gunter, W. Honnen, G. Krabichler, S. Schafler, S. Uhl - Pure Appl. Chem., 58 (1986) 1207 e referências aí citadas.

10. a) K. Kalyanasumdaram, J.K. Thomas - I. Am. Chem. Soc., 99 (1977) 2039; G. Beck, I.K. Thomas - Chem. Phys. Lett., 94 (1983) 553; J.K. Thomas - Chem. Rev, 93 (1993) 301 e referências ai citadas; I.K. Thomas - Chem. Rev., 80 (1980) 283; b) L. Francis, J. Lin, L.A. Singer Chem. Phys. Lett., 94 (1983) 162.
11. N.J. Turro, M.B. Zimmt, I.R. Gould - I. Am. Chem. Soc., 107 (1985) 5826; N.J. Turro, I.R Gould, M.B. Zimmt - Chem. Phys. Lett., 119 (1985) 484; N.J. Turro, C.C. Cheng, W. Mahler J. Am. Chem. Soc., 106 (1984) 5022; N.J. Turro - Pure Appl. Chem., 58 (1986) 1219.

12. J.C. Scaiano, H.L. Casal, J.C. Netto-Ferreira ACS Symp. Series, 13 (1985) 211; H.L. Casal J.C. Scaiano - Can. J. Chem., 62 (1984) 628; H.L. Casal, J.C. Scaiano - Can. J. Chem., 63 (1985) 1308; H.L. Casal, J.C. Netto-Ferreira, J.C. Scaiano - J. Inclusion Phenom., 3 (1985) 395; R. Boch, C. Bohne, J.C. Scaiano - J. Org. Chem., 61 (1996) 1423

13. F. Wilkinson, C.J. Willsher - Chem. Phys Lett., 104 (1984) 272; R W. Kessler, F. Wilkinson - J. Chem. Soc., Faraday Trans. I, 77 (1981) 309 F. Wilkinson - I. Chem. Soc., Faraday Trans. II, 82 (1986) 2073; R.W. Kessler, G. Krabichler, S. Schafler, S. Uhl, D. Oelkrug, W.P. Hagan, J. Hyslop, F. Wilkinson - Opt. Acta, 30 (1983) 1099; F. Winkinson, G.P. Kelly in "Photochemistry on Solid Surfaces", Eds. M. Anpo and T. Matsuara, Elsevier, Amsterdam, 1989, p. 31.

14. H. Ishida, H. Takahashi, H. Tsubomura - I. Am. Chem. Soc, 92 (1970) 275; H. Ishida, H. Tsubomura - J. Photochem., 2 (1973) 285.

15. R. Dabestani - Inter-Amer. Photochem. Soc. Newsletter, 20 (1997) 24

16. a) W.J. Albery, P.N. Bartlett, C.P. Wilde, J.R. Darwent - J. Am. Chem. Soc., 107 (1985) 1854; b) K.F. Scott - J. Chem. Soc., Faraday Trans, I, 76 (1980) 2065; c) A. Habti, D. Keravis, P. Levitz, H. Van Damme - J. Chem. Soc, Faraday Trans. II, 80 (1984) 67.

17. C.T. Lin, W.C. Hsu - J. Phys. Chem, 92 (1998) 1889; C.T. Lin, W.L. Hsu, M.A. El-Sayed - J. Phys. Chem, 91 (1987) 4556.

18. S. Suzuki, T. Fujii in "Photochemistry on Solid Surfaces" Eds. M. Anpo, T. Matsuara, Elsevier, Amsterdam, 1989, p. 77.

19. K. Kemnitz, T. Murao, I. Yamazaki, N. Nakashima, K. Yoshihara - Chem. Phys. Lett. 101 (1983) 337; K. Kemnitz, N. Tamai, I. Yamazaki, N. Nakashima, K. Yoshihara - J. Phys. Chem. 91 (1987) 1423; K. Kemnitz, N. Tamai, I. Yamazaki, N. Nakashima, K. Yoshihara - I. Phys. Chem. 91 (1986) 5094.

20. F. Wilkinson - Tetrahedron, 43 (1987) 1197; F. Wilkinson, D.R. Worrall - Proc. Indian Acad. Sci. (Chem. Sci.), 104 (1992) 287. 
21. A.D. French, N.R. Bertoniere, O.A. Battista, J. A. Cuculo, D.G. Gray - "Cellulose" in "UIImann's Encyclopedia of Industrial Chemistry", 4th Edn., VCH Publishers, New York, (1993), Vol. 3, p. 476.

22. O.A. Battista, "Microcrystalline Cellulose", in "Encyclopedia of Polymer Science and Technology", Eds.: H.F. Mark, N.G. Gaylord, N.M. Bikales, Wiley, New York, 1965, Vol. 3, p. 285.

23. T. Vo-Dinh, "Room-Temperature Phosphorimetry for Chemical Analysis", Wiley, New York, 1984.

24. a) E.M. Schulman, C. Walling - Science, $\mathbf{1 7 8}$ (1972) 53. b) E.M. Schulman, C. Walling - J. Phys. Chem., 77 (1973) 902. c) E.M. Schulman, R.T. Parker - J. Phys. Chem., 81 (1977) 1932.

25. a) T. Vo-Dinh, E.L. Yen, J.D. Winefordner Anal. Chem., 48 (1976) 1186 b) D.L. McAlease, R.B. Dunlap - Anal. Chem., 56 (1984) 2244.

26. J. Murtagh, J.K. Thomas - Chem. Phys. Lett., 148 (1988) 445.

27. a) L.F. Vieira Ferreira, M.R. Freixo, A.R. Garcia, F. Wilkinson - J. Chem. Soc. Faraday Trans, 88 (1992) 15. b) L.F. Vieira Ferreira, A.R. Garcia, M.R. Freixo, S.M.B. Costa - J. Chem. Soc. Faraday Trans., 89 (1993) 1937.

28. L.F. Vieira Ferreira, P.V. Cabral, P. Almeida, A.S. Oliveira, M.J. Reis, A.M. Botelho do Rego Macromolecules, 30 (1998) 3936.

29. a) L.F. Vieira Ferreira, M.J. Lemos, M.J. Reis, A.M. Botelho do Rego, Resultados não publicados. b) M.J. Lemos, L.F. Vieira Ferreira - "Photophysical properties of Rhodamine dyes adsorbed onto wet and dry microcrystalline cellulose" in Eurolights /I - Light on Organized Molecular Systems, Hengelhoef, Belgium, 1995, p. 90.

30. a) L.F. Vieira Ferreira, J.C. Netto-Ferreira, I.V. Khmelinskii, A.R. Garcia, S.M.B. Costa Langmuir, 11 (1995) 231. b) L.R. Ilharco, A.R. Garcia, J. Lopes da Silva, L.F. Vieira Ferreira Langmuir, 13 (1997) 4126. d) L.F. Vieira Ferreira, J.C. Netto-Ferreira, S.M.B. Costa - Spectrochim. Acta A, 51 (1995) 1385. e) J.C. Netto-Ferreira, L.F. Vieira Ferreira, S.M.B. Costa - Quim. Nova, 19 (1996) 1217. f) L.R. Ilharco, A.R. Garcia, J. Lopes da Silva, M.J. Lemos, L.F. Vieira Ferreira - Langmuir, 13 (1997) 3787.

31. a) L.F. Vieira Ferreira, M.J. Lemos, V. Wintgens, J.C. Netto-Ferreira, Quim. Nova, 00 (1998) 000. b) L.F. Vieira Ferreira, M.J. Lemos,
V. Wintgens, I.C. Netto-Ferreira - Spectrochim. Acta A, 00 (1998) 000.

32. F. Wilkinson, P.A. Leicester, L.F. Vieira Ferreira, V.M.M. Freire - Photochem. Photobiol., 54 (1991) 599 .

33. a) L.F. Vieira Ferreira, A.S. Oliveira, I.V. Khmelinskii, S.M.B. Costa - J. Luminesc., 60861 (1994) 485; b) F. Wilkinson, D.R. Worrall, L.F. Vieira Ferreira - Spectrochim. Acta A, 48 (1992) 135.

34. L.F. Vieira Ferreira, J.C. Netto-Ferreira, A.S. Oliveira, S.M.B. Costa - Bolet. Soc. Port. Quím., 60 (1996) 50.

35. a) A.S. Oliveira, L.F. Vieira Ferreira, F. Wilkinson, D.R. Worrall - J. Chem. Soc. Faraday Trans., 92 (1996) 4809. b) L.F. Vieira Ferreira, A.S. Oliveira, F. Wilkinson, D.R. Worrall - J. Chem. Soc. Faraday Trans., 92 (1996) 1217. c) L.F. Vieira Ferreira, A.S. Oliveira, K.H. Henbest, F. Wilkinson, D.R. Worrall - RAL CLF Annual Report, (1997) 143. d) A.S. Oliveira, P. Almeida, L.F. Vieira Ferreira - Coll. Czech .Chem. Comm., 64 (1999) 000.

36. a) A.M. Botelho do Rego, L. Penedo Pereira, M.J. Reis, A.S. Oliveira, L.F. Vieira Ferreira - Langmuir, 13 (1997) 6787. b) A.M. Botelho do Rego - Bolet. Soc. Port. Quím., 48 (1993) 28.

\section{H.E.A. Kramer - Chimia, 40 (1986) 160.}

38. N.S. Allen - Rev. Prog. Col., 17 (1987) 61.

39. L.M.G. Jansen, I.P. Wilkes, D.C. Greenhill, F. Wilkinson - J. Soc. Dyes Col., 114 (1998) 327

40. L.R. Snyder, J.W. Ward - I. Phys. Chem., 70 (1966) 3941.

41. N.J. Turro - Tetrahedron, 43 (1987) 1589.

42. W.J. Leigh, L. Johnston, "Handbook of Organic Photochemistry", Scaiano, I. C., Ed.; CRC Press, Boca Raton, 1989, Vol. 2, Cap. 22, p. 401, e referências aí citadas.

43. Aldrich Technical Information Bulletin, Number AL-144.

44. J. Nawrocki - J. Chromatography, 779 (1997) 29.

45. K.K. Unger, "Porous Silica", Elsevier, Amsterdam, 1979; R. Iler, "The Chemistry of Silica",
Wiley, New York (1979).

46. P. Van de Voort, I. Gillis-D'Hamers, E.F. Vansant, J. Chem. Soc. Faraday Trans., 86 (1992) 3751; I. Gillis-D'Hamers, I. Cornelissens, K.C. Vrancken, P. Van de Voort, E.F. Vansant, J. Chem. Soc. Faraday Trans., 88 (1992) 723.

47. a) E.M. Flanigen, J.M. Bennett, R.W. Grose, R.L. Patton, R.M. Kirchner, I.V. Smith Nature, 271 (1978) 512. b) G.M.W. ShultzSibbel, D.T. Gjerde, C.D. Chriswell, J.S. Fritz, W.E. Coleman - Talanta, 29 (1982) 447. c) G.T. Kokotailo, S.L. Lawton, D.H. Olson - Nature, 272 (1978) 437.

48. D.M. Bilby, N.B. Milestone, L.P. Aldridge Nature, 280 (1979) 664.

49. W. Wendlandt, H.G. Hecht, "Reflectance Spectroscopy", J. Wiley, New York, 1966.

50. P. Kubelka, F. Munk - Z. Tech. Phys, 12 (1931) 593.

51. G.P. Kelly, P.A. Leicester, F. Wilkinson, D.R. Worrall, L.F. Vieira Ferreira, R. Chittock, W. Toner - Spectrochim. Acta A, 46 (1990) 975.

52. D. Oelkrug, W. Honnen, C.J. Willsher, F. Wilkinson - I. Chem. Soc., Faraday Trans. I, 81 (1987) 2081.

53. a) P.P. Levin, L.F. Vieira Ferreira, S.M.B. Costa - Chem. Phys. Lett., 173 (1990) 277; b) P.P. Levin, L.F. Vieira Ferreira, S.M.B. Costa, I.V. Katalnikov - Chem. Phys. Lett., 193 (1992) 461; c) P.P. Levin, L.F. Vieira Ferreira, S.M.B. Costa Langmuir, 9 (1993) 1001; d) P.P. Levin, S.M.B. Costa, L.F. Vieira Ferreira - J. Phys. Chem., 100 (1996) 15171.

54. L.M. Ilharco - Bol. Soc. Port. Quím., 69 (1998) 34

55. N. Câmara de Lucas, J.C. Netto-Ferreira, J. Andraos, J. Lusztyk, B.D. Wagner, J.C. Scaiano Tetrahedron Lett., 38 (1997) 5147.

56. F. Wilkinson, L.F. Vieira Ferreira - /. Luminesc., $40 \& 41$ (1988) 704.

57. M. Gabriela Lagorio, L.E. Dicerio, M. I. Litter, H. San Roman - J. Chem. Soc. Faraday Trans., 94 (1998) 419.

58. L.F. Vieira Ferreira, S.M.B. Costa, E.J. Pereira - J. Photochem. Photobiol., A:Chem. - 55 (1991) 361 ; b) L.F. Vieira Ferreira, S.M.B. Costa - J. Luminesc., $48 \& 49$ (1991) 135. 


\section{EQUIPAMENTO DE VÁCUO}

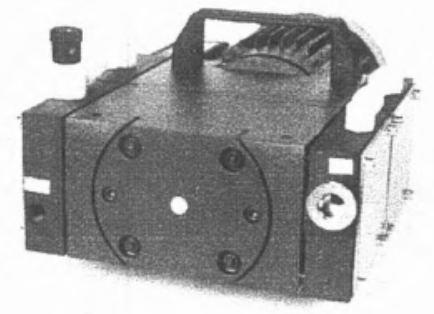

Sistemas de deposição térmica e de Sputtering Detectores de fugas Manipuladores de amostras

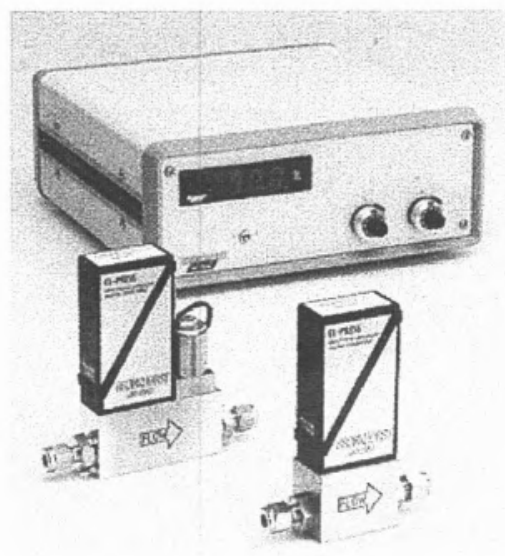

Bombas de membrana Bombas rotativas a óleo Bombas difusoras Bombas Turbomoleculares Bombas Roots Bombas quimicas secas Bombas lónicas

Válvulas, vedantes, flanges,óleos e "greases".

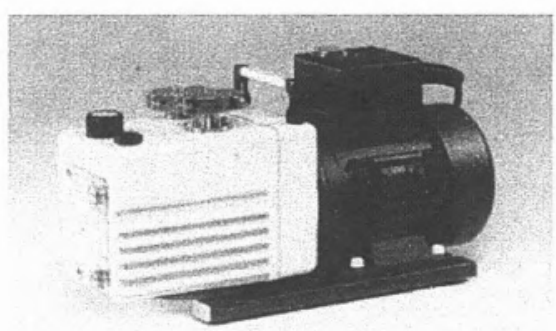

Medidores/controladores de vácuo:

- Piezoeléctricos, Piranis, Pennings, Capacitivos (Baratron) e Ion gauges. Medidores/controladores de Fluxo e Massa.

\section{LIOFILIZADORES}

\section{OUTROS EQUIPAMENTOS}

Balanças Analíticas. Banhos de Ultrasons. Banhos Termostáticos. Recirculadores. Geradores de Gases. Manoredutores. Fluxímetros. Manoredutores e Reguladores de Pressão. Compressores Silenciosos. Compressores Secos. Válvulas, Tubos e Coneç̧ões para Fluidos.

$S T V$ - Equipamentos para a Indústria e Laboratórios, Lda Casal da Serra, lote 103 - loja Esq.- 2625-082 Póvoa Santa Iria Tel. 01-9563007 Fax 01-9562997 E-mail stv@mail.telepac.pt 